\title{
Prediction Model of Mechanical Extending Limits in Horizontal Drilling and Design Methods of Tubular Strings to Improve Limits
}

\author{
Wenjun Huang, ${ }^{1,2}$ Deli Gao, ${ }^{2}$ and Yinghua Liu ${ }^{1}$ \\ ${ }^{1}$ School of Aerospace Engineering, AML, Tsinghua University, Beijing 100084, China \\ ${ }^{2}$ MOE Key Laboratory of Petroleum Engineering, China University of Petroleum, Beijing 102249, China \\ Correspondence should be addressed to Wenjun Huang; huangwenjun1986@126.com
}

Received 15 February 2017; Revised 27 April 2017; Accepted 3 May 2017; Published 24 May 2017

Academic Editor: Mohammed Nouari

Copyright (C) 2017 Wenjun Huang et al. This is an open access article distributed under the Creative Commons Attribution License, which permits unrestricted use, distribution, and reproduction in any medium, provided the original work is properly cited.

Mechanical extending limit in horizontal drilling means the maximum horizontal extending length of a horizontal well under certain ground and down-hole mechanical constraint conditions. Around this concept, the constrained optimization model of mechanical extending limits is built and simplified analytical results for pick-up and slack-off operations are deduced. The horizontal extending limits for kinds of tubular strings under different drilling parameters are calculated and drawn. To improve extending limits, an optimal design model of drill strings is built and applied to a case study. The results indicate that horizontal extending limits are underestimated a lot when the effects of friction force on critical helical buckling loads are neglected. Horizontal extending limits firstly increase and tend to stable values with vertical depths. Horizontal extending limits increase faster but finally become smaller with the increase of horizontal pushing forces for tubular strings of smaller modulus-weight ratio. Sliding slack-off is the main limit operation and high axial friction is the main constraint factor constraining horizontal extending limits. A sophisticated installation of multiple tubular strings can greatly inhibit helical buckling and increase horizontal extending limits. The optimal design model is called only once to obtain design results, which greatly increases the calculation efficiency.

\section{Introduction}

Extending limit in horizontal drilling is a constrained optimization problem in which horizontal extension of the wellbore is the objective function, and kinds of ground and down-hole constraint conditions and operation conditions in horizontal drilling are considered. There are two main issues in extending limits including prediction and control. Prediction refers to "what are the extending limits," and control means "how to increase the extending limits." Until now, some researchers have built models by considering several factors or analyzed the extending limits with drilling data, and a systematic theoretical framework of extending limits in rotary drilling is forming.

$\mathrm{Wu}$ and Juvkam-Wold [1] studied the effect of helical buckling on the slack-off extension limit of tubing in horizontal wells and pointed out that helical buckling can limit wellbore extension a lot. Mason and Judzis [2] analyzed the extending limits in shallow, mid-deep, and deep wells with drilling data and the results show that friction force is main constraint factor for shallow wells, drill rig capacity and tubular strength are for mid-deep wells, and tubular strength is for deep wells. Wang and Guo [3] built the models of extending limits by considering the effects of formation property, hydraulic equipment capacity, drill fluid property, and so on. Gao et al. [4] proposed the concepts of extending limits of extended-reach wells. They pointed out that extending limits can be further divided into three categories according to the properties of constraint conditions, including mechanical extending limits, open-hole extending limits, and hydraulic extending limits, for the convenience of analysis. Mechanical extending limit means the maximum wellbore extension under the constraints of drilling mode, tubular strength, drill rig capacity, and so on, open-hole 


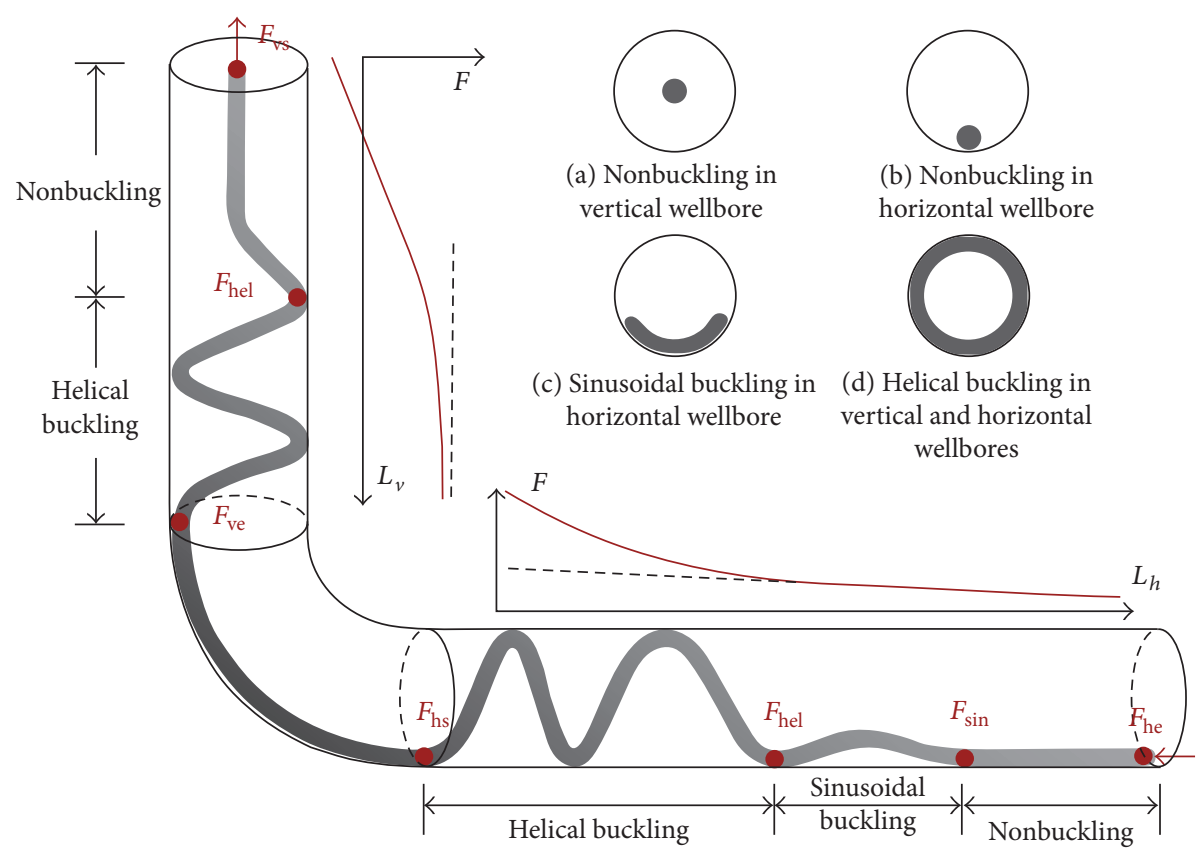

FIGURE 1: Buckling state of tubular strings in a horizontal well while slack-off.

extending limit means the maximum wellbore extension within which either collapse or fracture of the wellbore does not happen, and hydraulic extending limit means the maximum wellbore extension in which cutting removing is available under certain hydraulic parameters. Yan et al. [5] built theoretical models to predict the extending limits by considering the effects of rock breaking threshold, tubular strength, friction factor, and so on. Li et al. [6, 7] studied the open-hole extending limits by considering the effects of well path, drill fluid property, wellbore collapse and fracture, and so on in kinds of drilling scenarios. However, the above studies mainly focus the value of extending limit for a certain well and neglect the distributions of extending limits for kinds of wells. In other words, the law of the envelope of the extending limits for certain drill rig and down-hole constraint conditions is not revealed.

Until now, methods to improve mechanical extending limits have been discussed in previous studies. Peng and Zhao [8] proposed that drill collars or heavy weight drill pipes should be installed in the vertical wellbore to provide enough weight on bit, and common and heavy weight drill pipes should be adopted on the horizontal or holding section to reduce the axial friction. Han [9] proposed that the design of tubular string components should include the effects of rock breaking threshold, tubular failure, and tubular buckling. According to Han's studies, the objective functions of tubular string in sliding and rotary drilling modes should be, respectively, set to minimizing axial friction and minimizing tubular string weight. The tubular string components are constantly revised in iteration process. Allen et al. [10] studied the measures from the aspects of well path plan, drag reduction, and hydraulic parameters selection to improve extending limits with the case study of extendedreach wells in Wytch Farm. Xia et al. [11] proposed the design idea for tubular selection in extended-reach wells with trial and error method. The previous mechanical analysis of drill string behavior and design of tubular string components must be conducted several times to obtain an appropriate result in the previous methods, which means the design process is time-consuming and inefficient. Moreover, the previous design methods contain too much personal experience and lack of rigorous mathematical derivations.

In this paper, the mechanical extending limit model in horizontal drilling, in which kinds of ground and down-hole constraint conditions and operation conditions are included, is built. The proposed model is compared with other models in an example of four kinds of tubular strings. The law of distributions of mechanical extending limits is analyzed and the main factors constraining the wellbore extension are identified. A high-efficiency design method of drill strings components is built. At last, the extending limit model and design method are applied to a case study.

\section{Prediction Model of Mechanical Extending Limits}

2.1. Integral Mechanical Model. A typical horizontal well trajectory shown in Figure 1 includes three parts, namely, vertical, build-up, and horizontal wellbores. If a tubular string is in the pick-up process, the tubular strings in wellbores are in axial tensile state and the axis of tubular string is parallel to that of the wellbore. In the horizontal section, the tubular string lies on the bottom of wellbore due to gravity. In the build-up section, the tubular string touches the top or the bottom of the wellbore. In the vertical section, the tubular string stays on the wellbore axis and does not touch the inner surface of the wellbore. If the tubular string is in the slack-off operation, the mechanical behaviors of tubular 
strings become more complex. In the horizontal section, the tubular string is in axial compression state and the axial compressive force on the tubular string increases from the drill bit to the starting point of the horizontal section. If the axial force is smaller than the critical buckling load, the tubular string lies on the bottom of the wellbore. However, if the axial force exceeds the critical sinusoidal or helical buckling load, the tubular string enters into buckling state and the deflection curve of the tubular string is depicted by a sinusoidal curve or a helix. Therefore, buckling tends to occur on the starting part of the horizontal section shown in Figure 1. In the build-up section, the tubular string is usually in nonbuckling state for the buckling load is increased due to the effect of the curved wellbore configuration. Then, the tubular string tends to touch the bottom of the buildup wellbore. In the vertical wellbore, the axial compressive force increases with the increase of vertical depth. If the axial force is smaller than the critical helical buckling load, the tubular string keeps in straight line state. However, if the axial force exceeds the critical helical buckling loads, the tubular string becomes into helix state. Therefore, helical buckling tends to occur on the bottom part of the vertical wellbore.

Until now, down-hole mechanical model is the most effective method to calculate the mechanical behavior of down-hole tubular strings. The conventional integral mechanical model of down-hole tubular strings mainly developed from soft rope model (Johancsik et al. [12]), stiff rod model (Ho [13]), integral model based on basic equations of down-hole tubular mechanics (Gao et al. [14]), integral model including the tubular buckling effect (Wu and JuvkamWold [1]), and discrete integral model including the effect of connectors (Mitchell et al. [15]) to combined integral and mechanical model including the combined effects of connectors and buckling (Huang and Gao, [16]). In this paper, the buckling effect is included and connector is neglected. Further considering that the azimuth angles and bending curvatures of the wellbore axes are both equal to 0 for vertical, horizontal, and build-up sections of a horizontal wellbore, the axial force transfer on the tubular string is simplified as

$$
\frac{d(-F)}{d s}=-q \cos \alpha \mp \mu_{1} n_{t}
$$

where “ $\mp$ ” represents pick-up and slack-off operations, $F$ is the axial compressive force on the tubular string, $s$ is the well depth, $q$ is tubular weight per unit length, $\alpha$ is the inclination angle, $n_{t}$ is the contact force between tubular string and wellbore per unit length of the tubular string, and $\mu_{1}$ is the axial friction factor.

The torque transfer on the tubular string is calculated by

$$
\frac{d M_{T}}{d s}=-\frac{1}{2} \mu_{2} n_{t} D_{b}
$$

where $M_{T}$ is the torque on the tubular string, $\mu_{2}$ is the circumferential friction factor, and $D_{b}$ is the outer diameter of the tubular string. by

The bending moment on the tubular string is calculated

$$
M_{b}=E I \kappa_{b},
$$

where $M_{b}$ is the bending moment, $\kappa_{b}$ is the bending curvature of the wellbore axis, and $E I$ is the bending stiffness of the tubular string.

The contact force on the tubular string per unit length is expressed by

$$
\begin{aligned}
& n_{t} \\
& = \begin{cases}\left|\kappa_{b} F+q \sin \alpha\right| & F<F_{\text {sin }} \\
\left|\kappa_{b} F+q \sin \alpha\right| \cdot\left[1+\frac{4}{11}\left(\frac{F}{F_{\text {sin }}}-1\right)\right] & F_{\text {sin }} \leq F<F_{\text {hel }} \\
\frac{r_{b} F^{2}}{4 E I} & F \geq F_{\text {hel }},\end{cases}
\end{aligned}
$$

where $r_{b}$ is the radial clearance between the tubular string and wellbore and calculated by $r_{b}=\left(D_{w}-D_{b}\right) / 2$ and $F_{\text {sin }}$ and $F_{\text {hel }}$ are the critical sinusoidal and helical buckling loads.

The mechanical results of tubular strings in vertical, build-up, and horizontal wellbores under pick-up and slackoff operations are given in Appendix A.

2.2. Mechanical Extending Limit Model. Mechanical extending limit is a constrained optimization model with the length of well trajectory as the objective function, pick-up and slackoff in sliding and rotary modes as operation conditions, and drilling rig parameters, rock breaking thresholds, tubular strength, and so on as constrained conditions. Thus, the mechanical extending limit model is expressed by

$$
\text { Obj }=\max _{p \subset P} L(p, d, c),
$$

where $L$ is the well depth, $L()$ is an implicit function, namely, the integral mechanical model of down-hole tubular strings, $p$ is the constraint parameters such as drill rig capacity, tubular strength, $P$ is the allowable region for constraint parameters, namely, constraint conditions, $d$ is the design parameters such as well trajectory and tubular string components, and $c$ is the operation conditions including pick-up and slack-off in sliding and rotary modes. The integral mechanical model for a tubular string constrained in a horizontal well under kinds of operation conditions is given in Section 2.1 and Appendix A. In this section, the constraint conditions are given as follows.

For a certain drill rig, the rated pick-up force is a limited value. The axial tensile force on the top of the vertical section during pick-up is not larger than the rated pick-up force; namely,

$$
-F_{\mathrm{vs}} \leq T_{\text {rig }}{ }^{u},
$$

where $T_{\text {rig }}{ }^{u}$ is the rated pick-up force of the drill rig and $F_{\mathrm{vs}}$ is the axial force on the top of the vertical wellbore.

Meanwhile, the axial tensile force on the top of the vertical section during slack-off is not smaller than the minimum slack-off force; namely,

$$
-F_{\mathrm{vs}} \geq T_{\mathrm{rig}}{ }^{l},
$$


where $T_{\text {rig }}{ }^{l}$ is the minimum slack-off force of the drill rig and usually taken as 0 .

The torque on the top of the vertical section while rotating tubular string is not larger than the rated torque of the drill rig; namely,

$$
M_{\text {Tvs }} \leq M_{\text {Trig }}{ }^{u},
$$

where $M_{T \text { rig }}{ }^{u}$ is the rated torque of the drill rig and $M_{\text {Tvs }}$ is the torque on the top of the vertical wellbore.

In the drilling process, the axial force and torque on the drill bit must be not smaller than the threshold values of rock breaking; namely,

$$
\begin{aligned}
F_{\text {he }} & \geq F_{\text {ths }}{ }^{l} \\
M_{\text {The }} & \geq M_{\text {ths }}^{l} \approx k \cdot F_{\text {ths }}{ }^{l},
\end{aligned}
$$

where $F_{\text {ths }}{ }^{l}$ and $M_{T \text { ths }}{ }^{l}$ are the threshold values of axial force and torque for rock breaking, $k$ is the ratio of torque to axial force on the bit, and $F_{\text {he }}$ and $M_{\text {The }}$ are the axial force and torque on the end of the horizontal wellbore.

The average axial stress on the cross section of the tubular string due to axial force is calculated by

$$
\sigma_{m}=-\frac{F}{(\pi / 4)\left(D_{b}^{2}-D_{b i}^{2}\right)},
$$

where $\sigma_{m}$ is the average axial stress on the tubular string and $D_{b i}$ is the inner diameter of the tubular string.

The maximum shear stress on the cross section of the tubular string due to torque is calculated by

$$
\tau_{c}=-\frac{16 M_{T} D_{b}}{\pi\left(D_{b}^{4}-D_{b i}^{4}\right)},
$$

where $\tau_{c}$ is the maximum shear stress on the tubular string cross section.

The maximum bending stress on the cross section of the tubular string due to bending moment is calculated by

$$
\sigma_{b}=-\frac{32 M_{b} D_{b}}{\pi\left(D_{b}^{4}-D_{b i}^{4}\right)}
$$

where $\sigma_{b}$ is the maximum bending stress on the tubular string cross section.

According to the fourth strength theory (Han, [17]), the equivalent stress is calculated by

$$
\sigma=\sqrt{\left(\left|\sigma_{m}\right|+\sigma_{b}\right)^{2}+3 \tau_{c}^{2}} .
$$

To ensure the safety of tubular string, the equivalent stress must not be larger than the allowable stress; namely,

$$
\sigma \leq[\sigma]=\frac{\sigma_{s}}{n_{4}},
$$

where $\sigma$ is the equivalent stress, $[\sigma]$ is the allowable stress, $\sigma_{s}$ is the yielding strength of the tubular string, and $n_{4}$ is the safety factor.
2.3. Horizontal Extending Limits. A horizontal well can be divided into vertical-build and horizontal wellbores by the starting point of the horizontal wellbore. If the axial force and torque at the starting point of the horizontal wellbore are given, the axial force and torque transfer in the vertical-build wellbore can be obtained. Substituting the axial force and torque in the vertical-build wellbore, it can be determined whether the constraint expressions mentioned above are satisfied or not. Here three critical loads at the starting point of the horizontal section are defined, including minimum axial force $F_{\mathrm{hs}}{ }^{l}$, maximum axial force $F_{\mathrm{hs}}{ }^{u}$, and maximum torque $M_{\mathrm{Ths}}{ }^{u}$, under which the constraint conditions for tubular strings in vertical-build wellbore are just satisfied. The term $F_{\mathrm{hs}}{ }^{l}$ means the minimum axial force under which the tubular strings in the vertical-build wellbore are not yielded, and the axial tensile force on ground is not larger than the rated axial force on hook in the pick-up operation. The term $F_{\mathrm{hs}}{ }^{u}$ means the maximum axial force under which the axial tensile force on ground is not smaller than the minimum axial force on hook in the slack-off operation. The term $M_{\text {Ths }}{ }^{u}$ means the maximum torque under which the tubular strings are not yielded and torque on ground is not larger than the rated torque on rotary table. The calculation expressions of these three terms are given in Appendix B.

These three critical loads can also be seen as the constraint conditions in the mechanical analysis of tubular strings in the horizontal wellbores. According to the constraint conditions including $F_{\mathrm{hs}}{ }^{l}, F_{\mathrm{hs}}{ }^{u}, M_{\mathrm{Ths}}{ }^{u}$, rock breaking thresholds (9) and the axial force and torque transfer expressions of the extending limits of the horizontal wellbores can be determined.

For the pick-up operation in the sliding mode, the minimum axial force limits the wellbore extension, and the extending limit of the horizontal section is calculated by

$$
L_{h}=\frac{F_{\mathrm{he}}-F_{\mathrm{hs}}{ }^{l}}{\mu_{1} q},
$$

where $L_{h}$ is the limit length of the horizontal wellbore.

For the pick-up operation in the rotary mode, the maximum torque limits the wellbore extension and the extending limit is calculated by

$$
L_{h}=\frac{M_{T h s}{ }^{u}-M_{T h e}}{\mu_{2} D_{b} q / 2} .
$$

For the slack-off process in the sliding mode, the maximum axial force limits the wellbore extension and the extending limit is calculated by

$$
\begin{aligned}
& L_{h} \\
& = \begin{cases}\frac{\frac{F}{\mathrm{hs}}^{u}-F_{\mathrm{he}}}{\mu_{1} q} & F_{\text {hhel }} \geq F_{\mathrm{hs}}{ }^{u}>F_{\mathrm{he}} \\
\frac{4 E I}{\mu_{1} r_{b}}\left(\frac{1}{F_{h \text { hel }}}-\frac{1}{F_{\mathrm{hs}}{ }^{u}}\right)+\frac{F_{\text {hhel }}-F_{\mathrm{he}}}{\mu_{1} q} & F_{\mathrm{hs}}{ }^{u}>F_{h \text { hel }}>F_{\mathrm{he}} \\
\frac{4 E I}{\mu_{1} r_{b}}\left(\frac{1}{F_{\mathrm{he}}}-\frac{1}{F_{\mathrm{hs}}{ }^{u}}\right) & F_{\mathrm{hs}}{ }^{u}>F_{\mathrm{he}} \geq F_{h \text { hel }} \\
0 & \text { others. }\end{cases}
\end{aligned}
$$


TABLE 1: Values of the relevant parameters for different tubular strings.

\begin{tabular}{lccccc}
\hline Type & $D_{b}(\mathrm{~m})$ & $D_{b i}(\mathrm{~m})$ & $E(\mathrm{~Pa})$ & $q_{s}(\mathrm{~N} / \mathrm{m})$ & 361 \\
SDP & 0.149 & 0.131 & $2.07 E+11$ & 233 & $5.72 E+08$ \\
TDP & 0.149 & 0.131 & $1.14 E+11$ & 226 & $4.87 E+08$ \\
ADP & 0.149 & 0.131 & $6.96 E+10$ & 182 & $3.08 E+08$ \\
CDP & 0.149 & 0.131 & $3.79 E+10$ & $2.08 E+08$ \\
\hline
\end{tabular}

For the slack-off process in the rotary mode, the extending limit is equal to the minimum value of (16) and (17).

2.4. Comparison with Other Models. Here, the horizontal extending limits of a SDP constrained in horizontal wellbore for different models are studied. Friction factor and mud density are assumed to be 0.3 and $1677 \mathrm{~kg} / \mathrm{m}^{3}$. The diameter of the horizontal wellbore is $0.2159 \mathrm{~m}$. The values of other parameters are given in Table 1. Figure 2 shows the horizontal extending limits of SDP for Wu and Juvkam-Wold's [1] and Mehrabi and Miska's [18] models and the proposed model. Wu and Juvkam-Wold [1] have deduced the extending limit of coiled tubing in horizontal well. Similar to (17), the calculation expressions of horizontal extending limits for Wu's model are given by

$$
L_{h}= \begin{cases}\frac{F_{\mathrm{hs}}{ }^{u}-F_{\mathrm{he}}}{\mu_{1} q} & F_{h \text { hel }} \geq F_{\mathrm{hs}}{ }^{u}>F_{\mathrm{he}} \\ \frac{F_{h \mathrm{sin}}}{\mu_{1} q}\left(\arctan \frac{F_{\mathrm{hs}}{ }^{u}}{F_{h \sin }}-\arctan \frac{F_{h \text { hel }}}{F_{h s i n}}\right)+\frac{F_{h \text { hel }}-F_{\mathrm{he}}}{\mu_{1} q} & F_{\mathrm{hs}}{ }^{u}>F_{h \text { hel }}>F_{\mathrm{he}} \\ \frac{F_{h \text { sin }}}{\mu_{1} q}\left(\arctan \frac{F_{\mathrm{hs}}{ }^{\mathrm{u}}}{F_{h \sin }}-\arctan \frac{F_{\mathrm{he}}}{F_{h s i n}}\right) & F_{\mathrm{hs}}{ }^{u}>F_{\mathrm{he}} \geq F_{h \text { hel }} \\ 0 & \text { others, }\end{cases}
$$

in which $F_{h s i n}$ is the critical sinusoidal buckling load in horizontal wellbore for no friction case. Note that $F_{\text {hhel }}$ is the critical helical buckling load in horizontal wellbore considering friction force. The amendement factor $\lambda_{f}=$ $\lambda_{f}(\mu)$ means the ratio of critical helical buckling load for friction case to that for nonfriction case. The calculation expression of $\lambda_{f}$ is given in (A.8). The expression $\lambda_{f}=$ 1 means the critical helical buckling load for zero friction factor case, namely, friction-free critical helical buckling load.

The results show that the extending limits increase with the axial forces at the starting point of the horizontal section. If helical buckling does not occur on the horizontal section $\left(F_{\text {hs }}<F_{\text {hs_hel }}\right)$, the horizontal extending limits increase linearly. If helical buckling occurs $\left(F_{\mathrm{hs}} \geq F_{\mathrm{hs} \text { hel }}\right)$, the horizontal extending limits increase slowly and tend to stable values when axial forces tend to infinity. Note that horizontal extending limits can increase a lot even after helical buckling occurs. Therefore, the occurrence of helical buckling is too conservative to predict the horizontal extending limits.

For the friction-free critical helical buckling load, the extending limits in the new model are larger than that of Wu and Juvkam-Wold's [1] model. In Wu's derivation, the contact force is calculated by $n_{t}=r_{b} F^{2} / 4 E I+q \sin \alpha$ while $F \geq F_{\text {hel }}$ and it is larger than the contact force in (4) in helical buckling mode. Therefore, the axial force loss for Wu's model is larger than that in the new model and the horizontal extending limits for Wu's model are smaller than that in the new model when helical buckling occurs. However, when the helical buckling does not occur, the horizontal extending limits for these two models are equal.

For the friction-related critical helical buckling load, the horizontal extending limits are larger than that for frictionfree model. Therefore, if the effect of friction force on critical helical buckling load is neglected, the horizontal extending limits are underestimated a lot. In Mehrabi and Miska's [18] derivation, the effect of friction force on critical buckling load is considered, so the results for these two models are very close to each other. However, Mehrabi and Miska's [18] have not given the explicit calculation expressions of horizontal extending limits while considering the axial force and torque transfer in vertical and build-up wellbores. In this paper, a case study in which kinds of ground and down-hole constraint factors are comprehensively included is conducted and given in Section 2.5.

Here, several tubular strings of different parameters including SDP (steel drill string), TDP (titanium drill string), ADP (aluminum drill string), and CDP (composite drill string) are adopted and the extending limits are, respectively, calculated. The values of relevant parameters for these tubular strings are shown in Table 1 . The term $E / q_{s}$ means the ratio of Young's modulus of tubular string to tubular string weight per unit length (modulus-weight ratio). Note that modulusweight ratio decreases for tubular strings transform from 


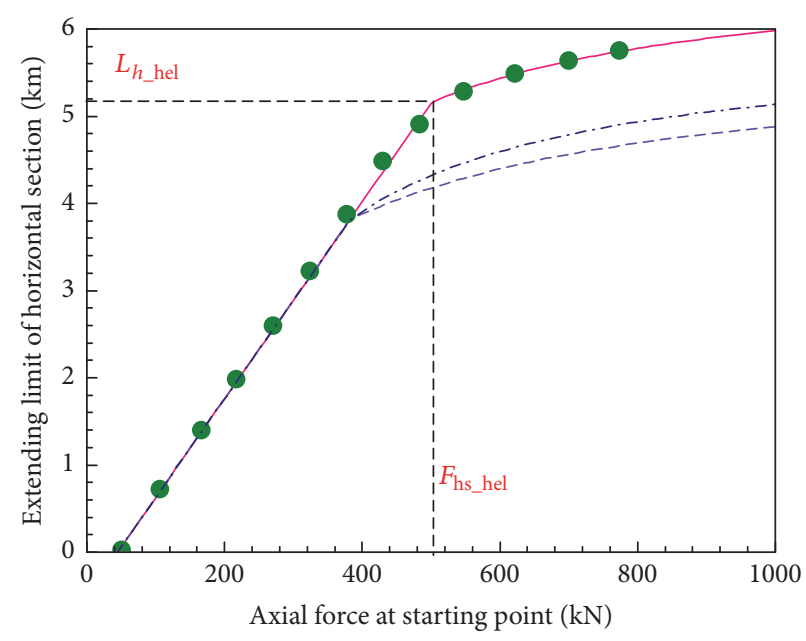

$$
\begin{aligned}
& \lambda_{f}=\lambda_{f}(\mu): \quad \lambda_{f}=1: \\
& \text { _ Huang and Gao (2016) _... Huang and Gao (2016) } \\
& \text { - Mehrabi and Miska (2015) - - - Wu and Juvkam-Wold (1995) }
\end{aligned}
$$

FIgURE 2: Horizontal extending limits for different models.

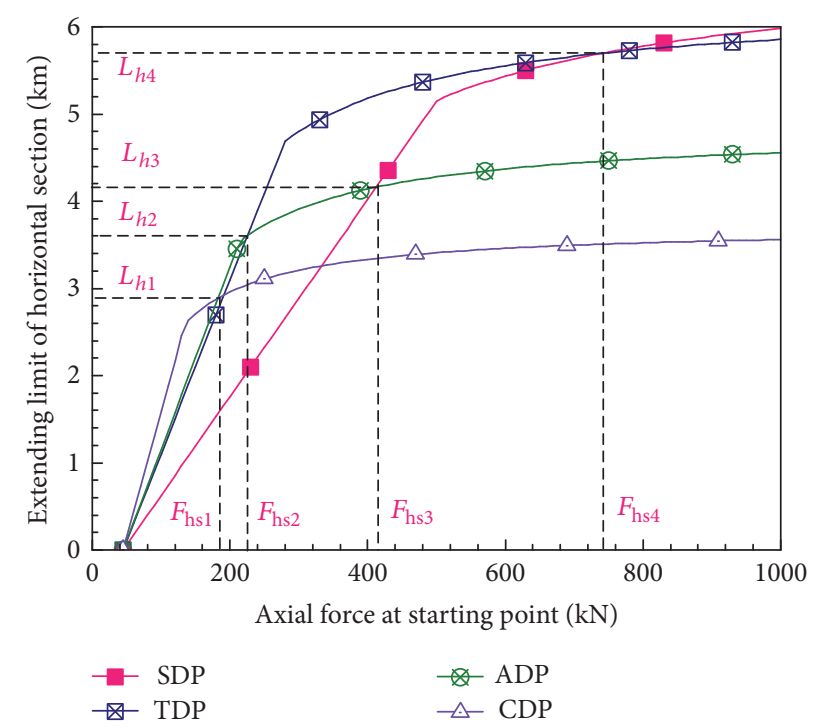

FIGURE 3: Horizontal extending limits for different tubular strings.

SDP, TDP, and ADP to CDP. The horizontal extending limits for different tubular strings are shown in Figure 3.

According to (17), horizontal extending limits increase faster for tubular strings of smaller weight per unit length when helical buckling does not occur. The horizontal extending limits when helical buckling just occurs increase with the increase of Young's modulus of tubular string. Meanwhile, the final extending limits when axial forces tend to infinity also increase with Young's modulus. Therefore, the distributions of horizontal extending limits are closely related to the combination of Young's modulus and tubular string weight per unit length, namely, modulus-weight ratio. Figure 3 shows that, for tubular strings of smaller modulus-weight ratio, the horizontal extending limits increase faster but the
TABLE 2: Axial forces and extending limits when helical buckling occurs.

\begin{tabular}{lcc}
\hline ID & $F_{\mathrm{hsi}}(\mathrm{kN})$ & $L_{\mathrm{hi}}(\mathrm{km})$ \\
\hline$i=1$ & 185 & 2.90 \\
$i=2$ & 225 & 3.60 \\
$i=3$ & 415 & 4.16 \\
$i=4$ & 745 & 5.70 \\
\hline
\end{tabular}

TABLE 3: Values of the relevant parameters in a case study.

\begin{tabular}{lc}
\hline Parameters & Values \\
\hline Kick-off depth $\left(L_{v}\right)$ & $2500 \mathrm{~m}$ \\
Build-up rate $\left(K_{\alpha}\right)$ & $6^{\circ} / 30 \mathrm{~m}$ \\
Inner diameter of wellbore $\left(D_{w}\right)$ & $311 \mathrm{~mm}$ \\
Outer diameter of tubular string $\left(D_{b}\right)$ & $127 \mathrm{~mm}$ \\
Rated pick-up force $\left(T_{\text {rig }}{ }^{u}\right)$ & $3000 \mathrm{kN}$ \\
Rated torque $\left(M_{T \text { rig }}{ }^{u}\right)$ & $50 \mathrm{kN} \cdot \mathrm{m}$ \\
Threshold axial force for rock breaking $\left(F_{\text {ths }}{ }^{l}\right)$ & $50 \mathrm{kN}$ \\
Threshold torque for rock breaking $\left(M_{T \text { ths }}{ }^{l}\right)$ & $5 \mathrm{kN} \cdot \mathrm{m}$ \\
\hline
\end{tabular}

final extending limits are smaller. Therefore, there is an intersection of extending limit curves for every two tubular strings. At the intersection, the extending limits and axial forces are both equal for these two tubular strings. For example, $F_{\mathrm{hs} 1}$ and $L_{h 1}$ are the intersection for CDP and ADP. When the axial force is smaller than $F_{\mathrm{hs} 1}$ or the designed horizontal length is smaller than $L_{h 1}$, CDP is superior to ADP. Conversely, ADP is superior to CDP. Other intersections are shown in Table 2. Therefore, the intersection provides a criterion for optimal section of tubular strings in horizontal drilling.

Overall, TDP is the most optimal solution to increase horizontal extending limits. However, the cost of TDP is also the highest, which limits its application. CDP is not recommended for application for its rather small finial extending limits. Therefore, SDP and ADP are the two common kinds of tubular strings in engineering application. The results show that SDP is more suitable for high axial forces even when helical buckling occurs and ADP is more suitable for small forces when helical buckling does not occur. Therefore, a more optimal solution is combination of ADP and SDP. The optimal design of multiple kinds of tubular strings is studied in Section 3.

2.5. Case Studies. In the above section, only the horizontal section is considered. In this section, the entire horizontal well including vertical, build-up, and horizontal wellbores is taken as the research object. A virtual case study is conducted to analyze the extending limits of a SDP in horizontal drilling. The axial friction factor in sliding mode is $\mu_{1}=0.25$, and the axial and circumferential friction factors in rotary mode are $\mu_{1}=0.1$ and $\mu_{2}=0.25$. The values of the other parameters are given in Table 3. The extending limits in slack-off and pickup conditions in the sliding and rotary drilling modes are studied, in which the friction-free helical buckling model is adopted. 


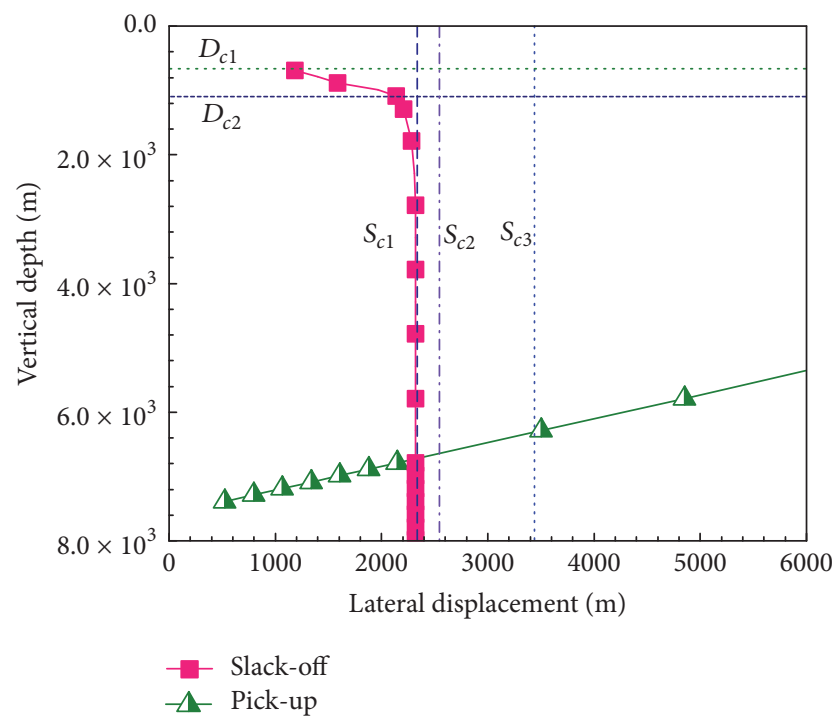

FIGURE 4: Extending limits of horizontal wells under sliding mode.

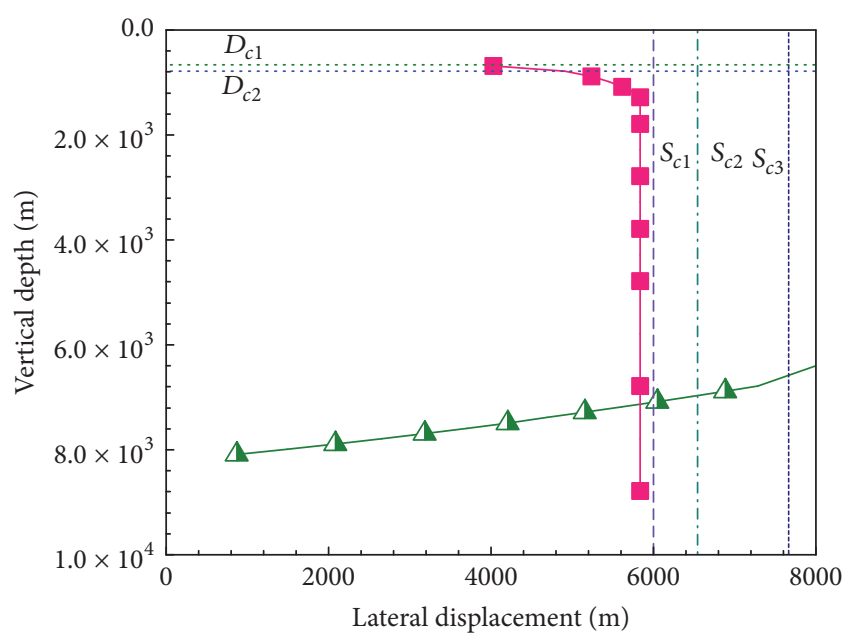

- Slack-off

FIGURE 5: Extending limits of horizontal wells under rotary mode.

Figures 4 and 5 show the slack-off and pick-up extending limits of horizontal wells in sliding and rotary modes. The red line represents the extending limits in the slack-off operation and the green line represents the extending limits in the pick-up operation. The left region which is surrounded by the slack-off and pick-up limits represents the areas that the drill rig can drill to and the boundaries of this region are the extending limits of the horizontal well. The term $D_{c 1}$ means the critical vertical depth within which the tubular string in vertical wellbore is in the nonbuckling state in the slack-off mode. The term $D_{c 2}$ means the critical vertical depth exceeding which helical buckling occurs on the horizontal section. When the vertical well depth $L_{v}$ is smaller than $D_{c 2}$ and larger than $D_{c 1}$, helical buckling occurs on the vertical section but does not on the horizontal section. When $L_{v}$ is larger than $D_{c 2}$, helical buckling occurs on both vertical and horizontal sections.
As is shown in Figure 4, slack-off is the operation condition which limits the wellbore extension in horizontal drilling except that the vertical depth is very large. For the slack-off process, the extending limits increase with the vertical well depth and approach the yielding values, namely, line $S_{c 1}$. Since contact force increases in square function with axial force on helical buckling section shown in (4), helical buckling increases the contact force and decreases the axial force transfer, which leads to the yield of extending limit curve. Note that $S_{c 1}$ corresponds to the case that the axial force on the end of the vertical section $F_{\mathrm{ve}}$ reaches its maximum value $F_{v \max }$. If $F_{v e}$ tends to infinity, the extending limits are the line $S_{c 2}$. If $F_{\mathrm{hs}}{ }^{u}$ is assumed to be infinity, the extending limits are the line $S_{c 3}$. Increasing the axial force transfer in the vertical and built-up wellbores which means $F_{\mathrm{hs}}{ }^{u}$ is increased has very limited contribution to increase the extending limits. The most important reason is that helical buckling can lead to high axial friction on tubular strings or even "lockup" in the slack-off process in the horizontal wellbore. The most important measure is to inhibit helical buckling in the horizontal well, which is discussed in Section 3.

Compared with the sliding mode, the extending limits in the rotary mode become larger in the rotary mode shown in Figure 5, since rotating tubular strings can decrease the axial friction forces. However, the extending limits also approach the yield values similar to the sliding mode. When the rotated tubular string reaches its extending limit, helical buckling is a rather serious problem. Serious helical buckling leads to high contact force, which further leads to high torque loss. Considering that serious helical buckling is caused by high axial friction on the horizontal wellbore, the coupled effect of helical buckling and axial friction is the main factor constraining the rotary extending limits. Therefore, the extending limits caused by minimum axial force are very close to that by maximum torque on the starting point of the horizontal section. To further increase the extending limits, inhibiting helical buckling on the horizontal section and increasing the rated torque on the rotary table are indispensable.

Figure 6 shows the extending limits under different friction factors. The results show that the extending limits increase with the decrease of friction factor. Since the friction factor is decreased, the axial force transfer loss is also decreased. The decrease of axial force loss weakens the helical buckling phenomenon on the helical buckling section, which decreases the contact force and further decreases the axial friction and torque loss. Therefore, the increasing rate of extending limits becomes larger with the decrease of friction factor shown in Figure 6.

Figure 7 shows the extending limits of horizontal wells under different drill rigs and the results indicate that drill rig capability affects vertical extending limits a lot. This is because the minimum axial force $F_{\mathrm{hs}}{ }^{l}$ which is closely related to the rated axial force of the drill rig is the main factor for wellbore extension. For shallow wells, drill rig capability affects the extending limits very little, for the main factor $F_{\mathrm{hs}}{ }^{u}$ is nearly irrelevant to the drill rig capacity. However, the maximum torque $M_{T h s}{ }^{u}$ which is close to the rate torque of the drill rig constraints the rotary extending limits when the rated torque of the drill rig is small. Therefore, axial friction 


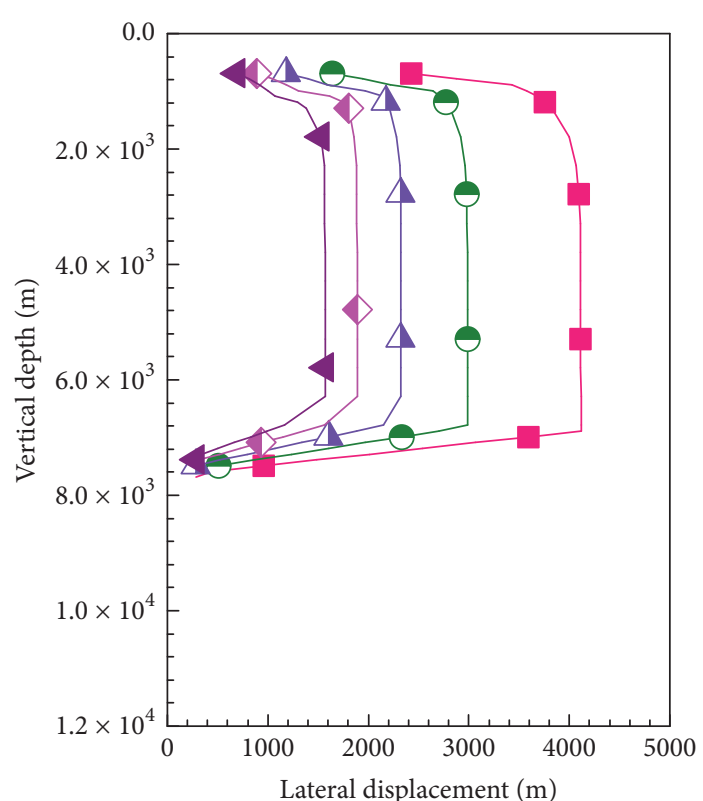

Friction factor $\left(\mu_{1}\right)$ :

$\begin{array}{llll}- & 0.15 & \searrow & 0.3 \\ - & 0.2 & \succ & 0.35 \\ -1 & 0.25 & & \end{array}$

(a) Sliding mode

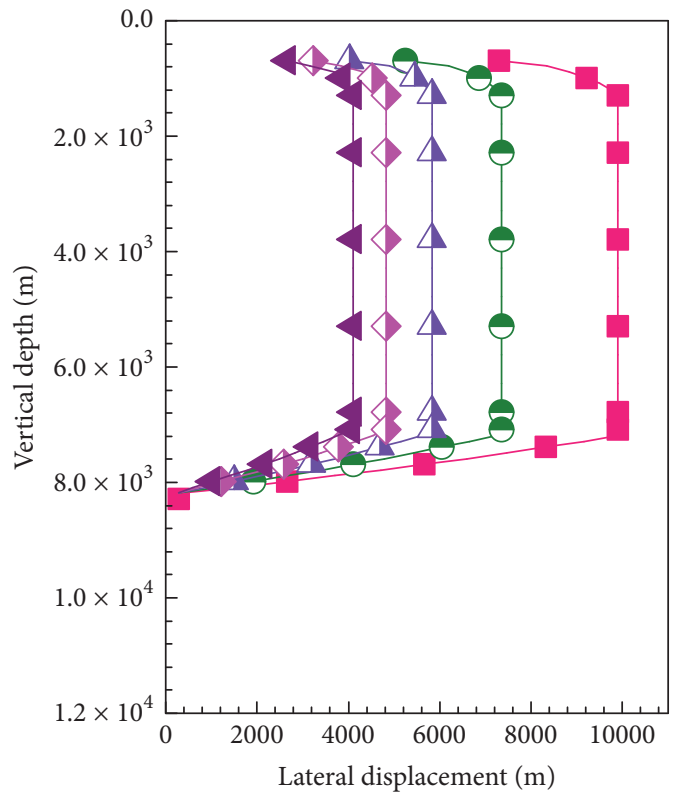

Friction factor $\left(\mu_{1}, \mu_{2}\right)$ :

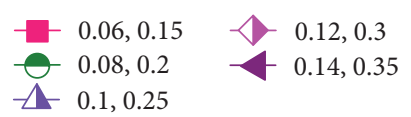

(b) Rotary mode

FIGURE 6: Extending limits of horizontal wells under different friction factors.
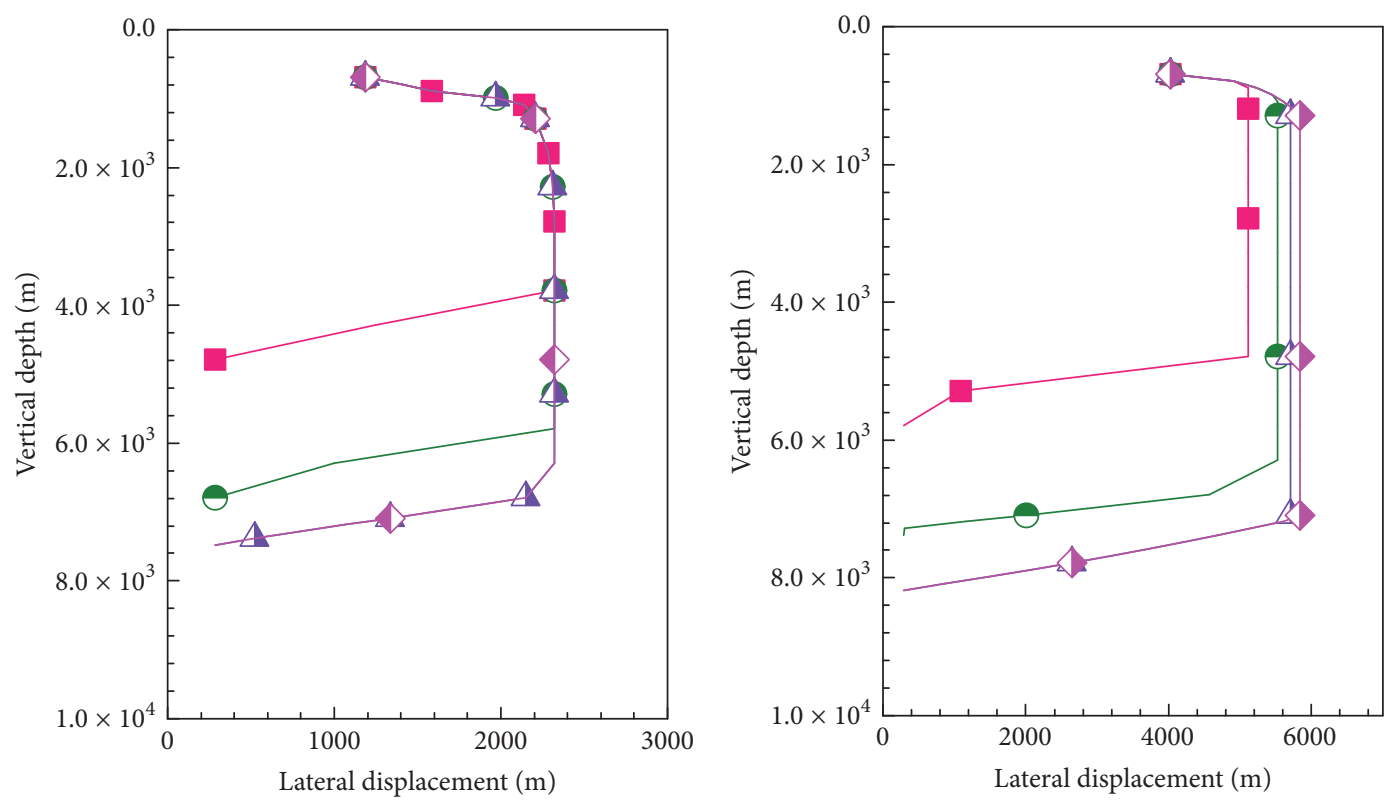

Drill rig: $T_{\text {rig }}{ }^{u}$

$-1500 \mathrm{kN}$

$-2500 \mathrm{kN}$

$\downarrow 3000 \mathrm{kN}$

(a) Sliding mode

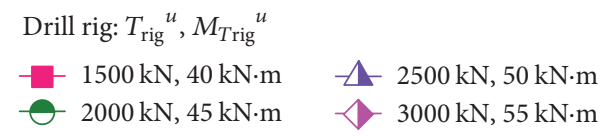

(b) Rotary mode

FIGURE 7: Extending limits of horizontal wells under different drill rigs. 


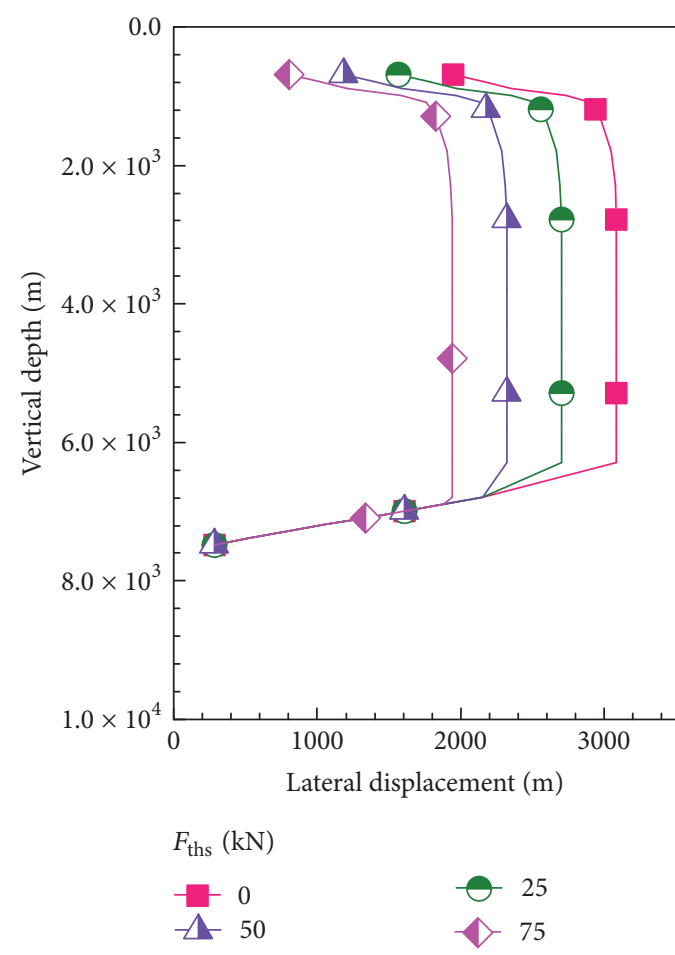

(a) Sliding mode

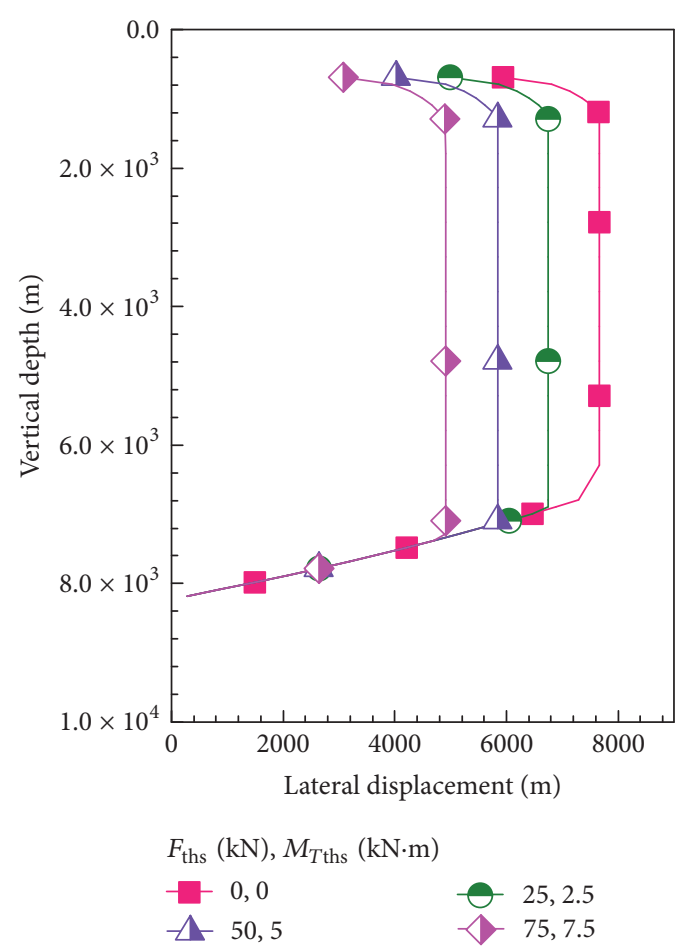

(b) Rotary mode

FIGURE 8: Extending limits of horizontal wells under different rock breaking threshold values.

and helical buckling are the primary factors and drill rig capacity is the secondary factor constraining the wellbore extension in shallow horizontal drilling.

Figure 8 shows the extending limits of horizontal wells under different rock breaking threshold values. The results indicate that the horizontal extending limits decrease with the increase of rock breaking threshold values. The rock breaking thresholds correspond to the axial forces on the bit $F_{\text {he }}$, and the change of $F_{\text {he }}$ is proportional to that of the horizontal extending limits $L_{h}$ shown in (B.10) when $F_{h e}>F_{h \text { hel }}$. Therefore, drill bits which match underground rock which means $F_{\text {ths }}$ is small should be adopted to increase extending limits.

Figure 9 shows the extending limits of horizontal wells under different tubular strengths. When the vertical depth is large, pick-up is the operation condition corresponding to the extending limits and tubular strength is the constraint condition. However, when the vertical depth is small, slackoff is the operation condition corresponding to the extending limits and high friction force is the constraint condition. Therefore, tubular strength affects vertical extending limits a lot but does not affect horizontal extending limits.

Figure 10 shows the extending limits of horizontal wells under different tubular diameters. Increasing tubular diameter can inhibit tubular buckling and reduce axial friction on the helical buckling section, so the extending limits increase with the increase of tubular diameter. However, the axial friction in the nonbuckling section can also be increased with the increase of tubular diameter, so the increasing rate of the extending limits becomes lower. With the increase of tubular diameter, the effect of inhibiting tubular buckling becomes smaller and meanwhile the effect of increasing axial friction in the nonbuckling section becomes larger. When the tubular diameter is rather large, the extending limits become smaller with the increase of tubular diameter. Therefore, several kinds of tubular string components should be adopted and optimized to increase extending limits.

\section{Optimal Design Method of Down-Hole Tubular Strings}

According to the above studies, tubular strings of multiple types and sizes are superior to that of single type and size. The previous studies on the section of tubular strings are most empirical or too complicated for application. In this section, a more high-efficiency design method of tubular strings is proposed.

Considering that an integral tubular string in a horizontal well can be divided into many local tubular strings, design problem for an integral tubular string can also be correspondingly divided into many subdesign problems of local tubular strings. The local and integral design problems of tubular string components are studied as follows.

3.1. Local Design Method of Tubular Strings. The above analyses show that slack-off is the most common operation condition which corresponds to the extending limits in horizontal drilling. Therefore, the optimal design of downhole tubular components mainly considers the slack-off case. 

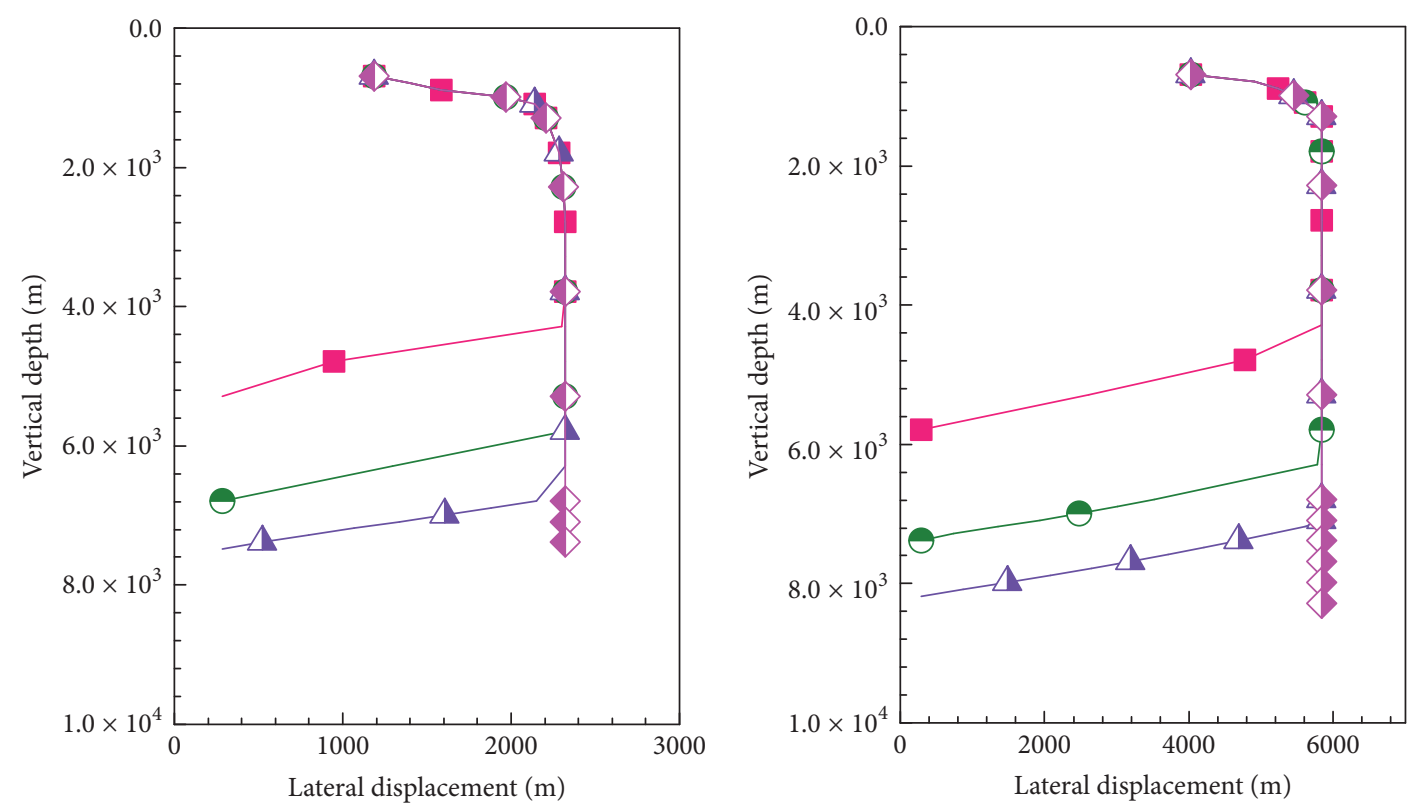

Yield strength $\sigma_{s}(\mathrm{MPa})$

$\begin{array}{ll}\text { — E: } 517.11 & \text { X: } 655.00 \\ - \text { G: } 723.95 & -\end{array}$

(a) Sliding mode

FIGURE 9: Extending limits of horizontal wells under different tubular strengths.
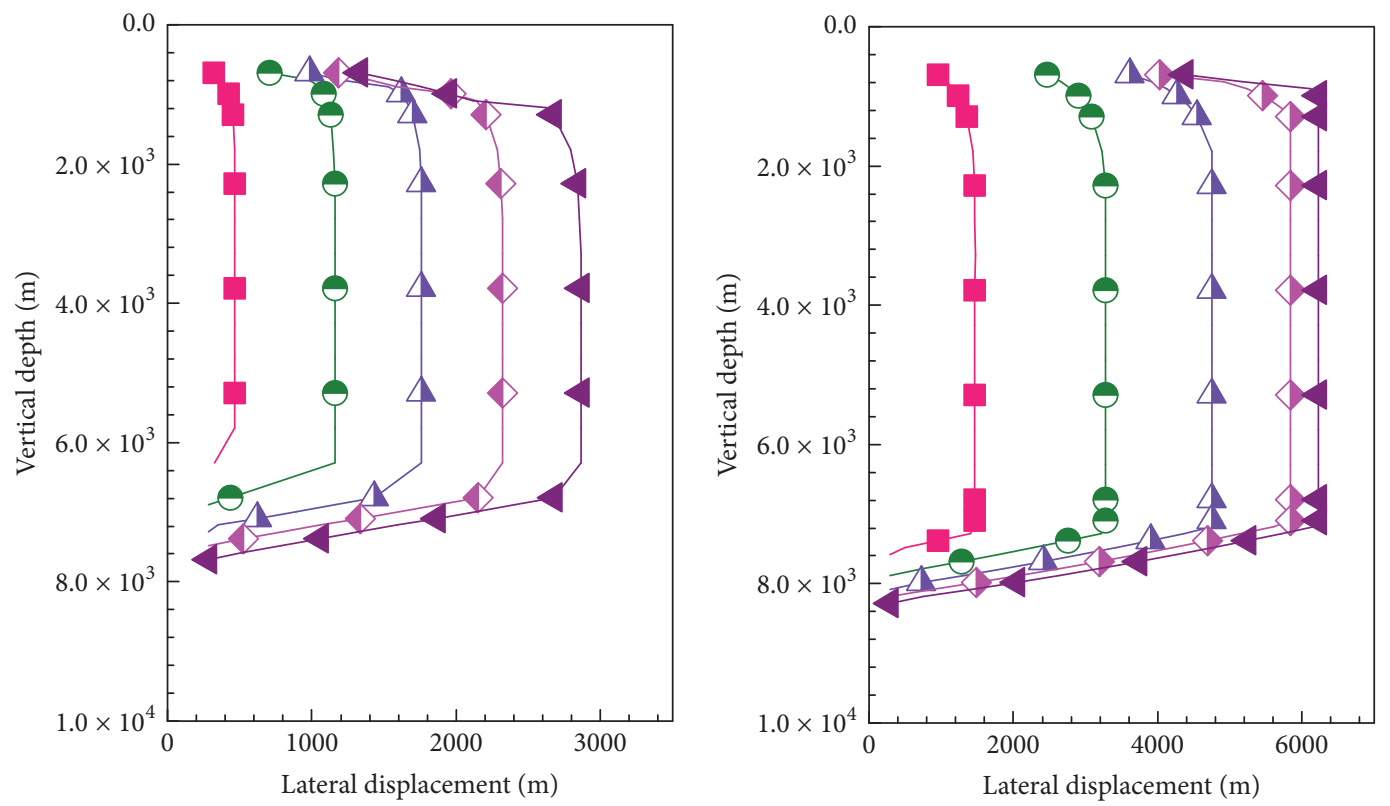

Tubular diameter $D_{b}$ (inch)

$\begin{array}{rr}-3.5 & \checkmark 5.0 \\ -4.0 & \succ 5.5 \\ -4.5 & \end{array}$

(a) Sliding mode (b) Rotary mode 
Rotating tubular string can increase the extending limits a lot, for friction force vector is moved from axial direction to circumferential direction in the rotary mode and the axial friction factor decreases a lot. Some other methods to reduce friction factor such as lubricate drilling mud and installing drag reducing tools also can increase the extending limits. Figures 4 and 5 indicate that the occurrence of helical buckling on the horizontal section leads to the extending limits approaching the yield values. Therefore, inhibiting helical buckling on the horizontal section is an important factor to increase the extending limits. According to (B.10), increasing the maximum axial force on the starting point of the horizontal section $\left(F_{\mathrm{hs}}{ }^{u}\right)$ also contributes to the increase of extending limits. Therefore, there are four principles which can be adopted to increase the horizontal extending limits: (1) rotating tubular string, (2) reducing friction factor, (3) inhibiting helical buckling, and (4) increasing the pushing force $F_{\mathrm{hs}}$. In this paper, the design method of tubular string components based on principles (3) and (4) to improve the mechanical extending limits is focused.

For a local tubular string, the design model for maximizing the axial force and torque transfer efficiency is expressed by

$$
\begin{aligned}
\min & \frac{d F,\left(M_{T}\right)}{d s}\left(d_{\text {tub }}\right) \\
& d_{\text {tub }} \in\left\{d_{\text {tub }}{ }^{1} \cdots d_{\text {tub }} N_{T}\right\},
\end{aligned}
$$

where $(d F / d s)\left(d M_{T} / d s\right)$ is the axial force (torque) transfer efficiency on the tubular string. The term $d_{\text {tub }}$ presents the relevant parameters for specified tubular strings. Considering that only several types (such as $N_{T}$ in (19)) of drill strings are manufactured, $d_{\text {tub }}$ distributes discretely. The term $d_{\text {tub }}$ is depicted by the outer diameter, inner diameter, Young's modulus, and so on of the drill string. The optimal results $\left(d_{\text {tub }}{ }^{*}\right)$ of (19) can be obtained with exhaustion method.

3.2. Integral Design Method of Tubular Strings. The design objective of an integral drill string is to maximum the axial force or torque from the ground to drill bit. As mentioned above, an integral tubular string is divided into $N$ local tubular strings, so the axial force and torque transfer on an integral tubular string are the sum of those on $N$ local tubular strings. Therefore, the objective function of the integral tubular string is the sum of those of $N$ local tubular strings. Then, the integral design model of tubular string components is expressed by

$$
\begin{aligned}
& \min \quad F_{\mathrm{vs}}-F_{\mathrm{he}}\left(, M_{\text {Tvs }}-M_{\text {The }}\right) \\
& =\min \sum_{i=1}^{N} \frac{d F_{i},\left(M_{T, i}\right)}{d s}\left(d_{\mathrm{tub}, i}\right) \Delta s_{i} \\
& \forall i, d_{\text {tub }, i} \in\left\{d_{\mathrm{tub}}{ }^{1} \cdots d_{\mathrm{tub}} N_{T}\right\},
\end{aligned}
$$

where $F_{\mathrm{vs}}-F_{\mathrm{he}}$ is the axial force transfer from the ground to drill bit, $M_{T \mathrm{vs}}-M_{T h e}$ is the torque transfer from the ground to drill bit, and $\Delta s_{i}$ is the length of the $i$ th local tubular string.
Note that, there are $N$ design variables in (20) and there are $N_{T}$ possible values for the design variables. If the exhaustion method is used to obtain the optimal solutions, the local mechanical model is called $\left(N_{T}\right)^{N}$ times, which takes two much calculation time when $N$ is large.

Take the Nth local tubular string adjacent to the drill bit as the research object. Considering that the axial force and torque on the right end of the $N$ th local tubular string, which are also the axial force and torque on the drill bit, are given in advance, the optimal design results can be obtained with the local design model on the $N$ th local tubular string. After the optimal results for $N$ th local tubular string are obtained, the axial force and torque on the left end of the $N$ th local tubular string, which are also the axial force and torque on the right end of the $(N-1)$ th local tubular string, are also calculated. Then, the optimal results for the $(N-1)$ th local tubular string can be calculated similar to the $N$ th local tubular string. The above procedure is conducted from the Nth local tubular string near the drill bit to the first local tubular string near the drill. Then, the integral design model of tubular string components is expressed by

$$
\begin{aligned}
\min & \frac{d F_{i},\left(M_{T, i}\right)}{d s}\left(d_{\mathrm{tub}, i}\right) \\
& d_{\mathrm{tub}, i} \\
& \in\left\{d_{\mathrm{tub}}{ }^{1} \cdots d_{\mathrm{tub}} N_{T}\right\} \quad(i=N, N-1, \ldots, 1) .
\end{aligned}
$$

Equation (21) means that the local design problem of $i$ th local tubular string is affected by the $(i+1)$ th to $N$ th local tubular strings but irrelevant to first to $(i-1)$ th local tubular strings. The integral design problem is equivalent to sequential local design problems (19) from $N$ th to first local tubular string. That means the integral design problem is a simple accumulation of $N$ local design problems. Then, the local mechanical model is called $\left(N_{T}\right) \times N$ times to obtain the optimal solution, which greatly decreases the calculation complexity.

3.3. Case Studies. The above models are applied to a virtual case study. A horizontal well is drilled, of which the kick-off depth is $2500 \mathrm{~m}$. The other parameters have been given in Section 2.5. Figure 11 shows the axial force distributions for different $5^{\prime \prime}$ drill string components including SDP, HWSDP (heavy weight steel drill string), and ADP. With the increase of well depth, the axial force firstly increases and then decreases. The left end represents the axial force on hook and the right end the axial force on drill bit. When the horizontal section length reaches $1960 \mathrm{~m}$, the axial force on hook increase to 0 , which means the drill string cannot move forward further and reaches its extending limit, namely, $1960 \mathrm{~m}$. Figure 12 shows the buckling state distributions for different drill string components, in which " 0 " means nonbuckling, " 1 " sinusoidal buckling, and " 2 " helical buckling. For the ordinary drill string, helical buckling occurs on the vertical wellbore and the starting part of the horizontal wellbore. If HWSDP is adopted and installation position is optimized, the axial force on hook decreases by about $1.4 * 10^{6} \mathrm{~N}$. Figure 13 shows the tubular type distributions 


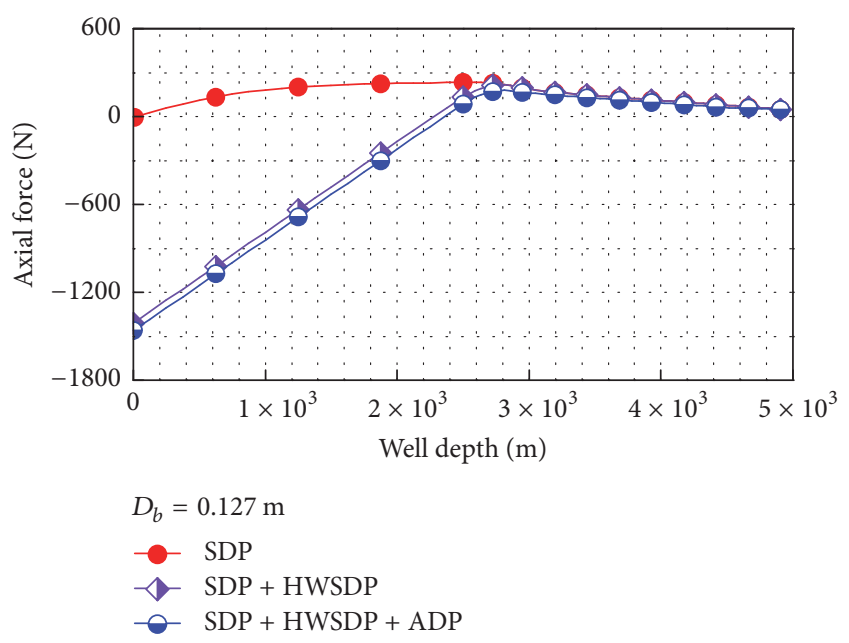

FIgURE 11: Axial force distributions for different drill string components.

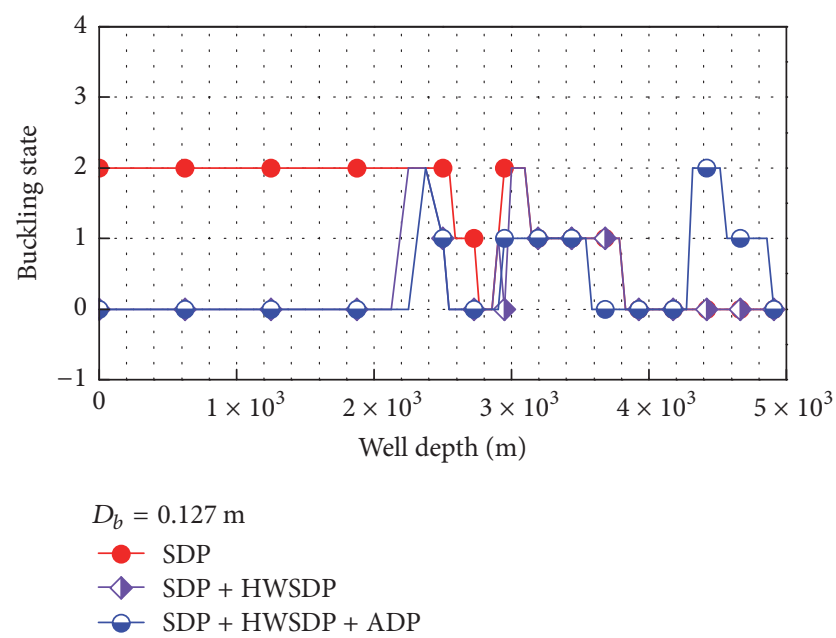

FIgURE 12: Buckling state distributions for different drill string components.

along the wellbore, in which 1 means SDP, 2 HWSDP, and 3 ADP. The results show that HWSDP should be installed on vertical wellbore, build-up wellbore, and the starting section of the horizontal wellbore to inhibit helical buckling and increase the maximum axial force on the starting point of the horizontal wellbore. Then, the horizontal wellbore extension can exceed the initial limit $1960 \mathrm{~m}$ and become larger. If ADP is further adopted, the axial force on hook can be decreased further. ADP should be installed on the end part of the horizontal wellbore to reduce the drill string weight and axial friction force [19].

Figure 14 shows the axial forces on hook under different horizontal wellbore lengths for different drill string components in the sliding drilling mode. The axial forces on hook increase faster and faster with horizontal wellbore length due to the existence of helical buckling. The horizontal extending limit is equal to the horizontal wellbore length at which the axial force on hook is 0 . When the horizontal wellbores approach the extending limits, the axial forces on the hook change a lot, but the horizontal extension lengths nearly keep

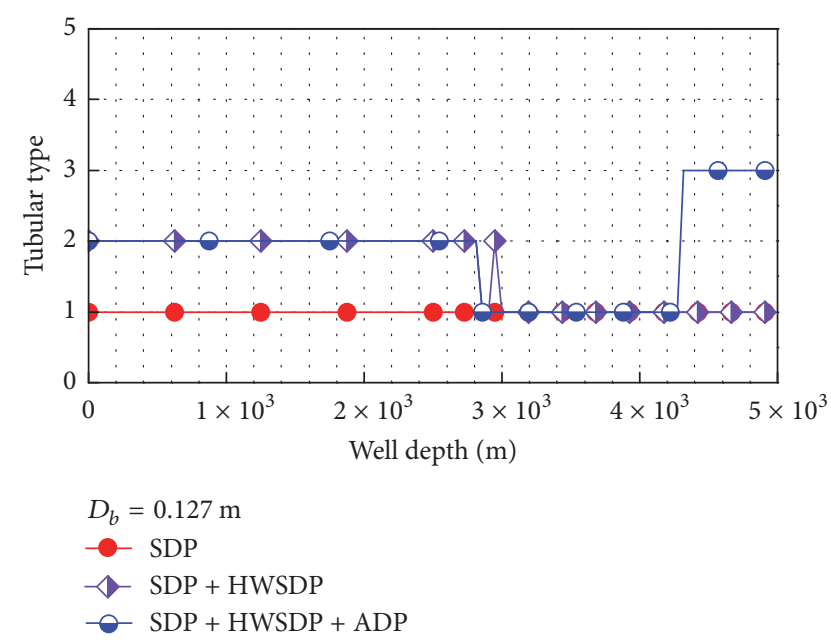

FIgURE 13: Tubular type distributions for different drill string components.

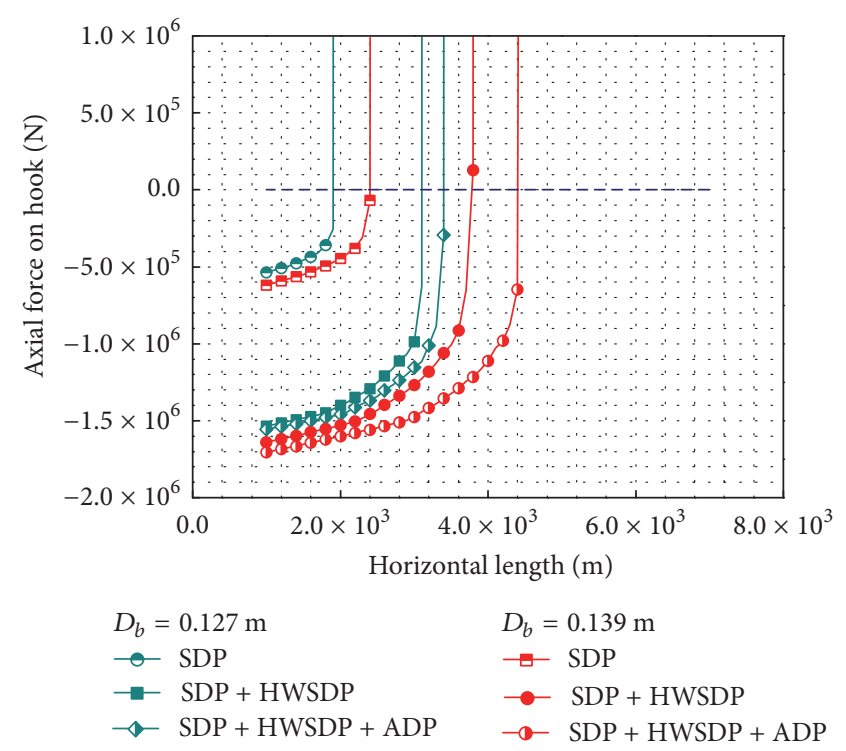

FIGURE 14: Axial forces on hook for different drill string components in sliding drilling mode.

unchanged. This phenomenon is also called "lock-up" in drilling engineering. If the weight of hook is further applied on the drill string, which means the axial forces on the hook are further increased, the horizontal wellbore cannot be further extended. To extend the horizontal extending limit, drill string components should be optimized. The horizontal extending limits for the $5^{\prime \prime}$ SDP, SDP + HWSDP, and SDP + HWSDP + ADP are, respectively, about $1900 \mathrm{~m}, 3100 \mathrm{~m}$, and $3400 \mathrm{~m}$ and for $5.5^{\prime \prime}$ SDP, SDP + HWSDP, and SDP + HWSDP + ADP are, respectively, about $2400 \mathrm{~m}, 3700 \mathrm{~m}$, and $4500 \mathrm{~m}$.

Figures 15 and 16, respectively, show the axial forces on hook and torques on rotary table under different horizontal wellbore lengths for different drill string components in the rotary drilling mode. The results show that the horizontal extending limits due to torques on rotary table are smaller than that due to axial forces on hook. This is because helical buckling is serious when the horizontal wellbore approaches 


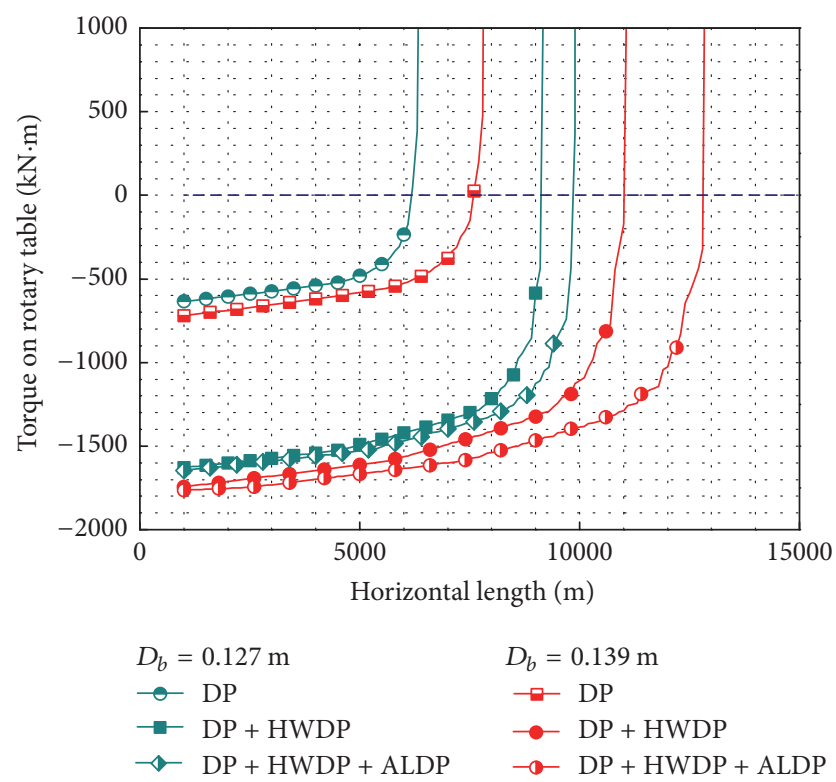

FIGURE 15: Axial forces on hook for different drill string components in rotary drilling mode.

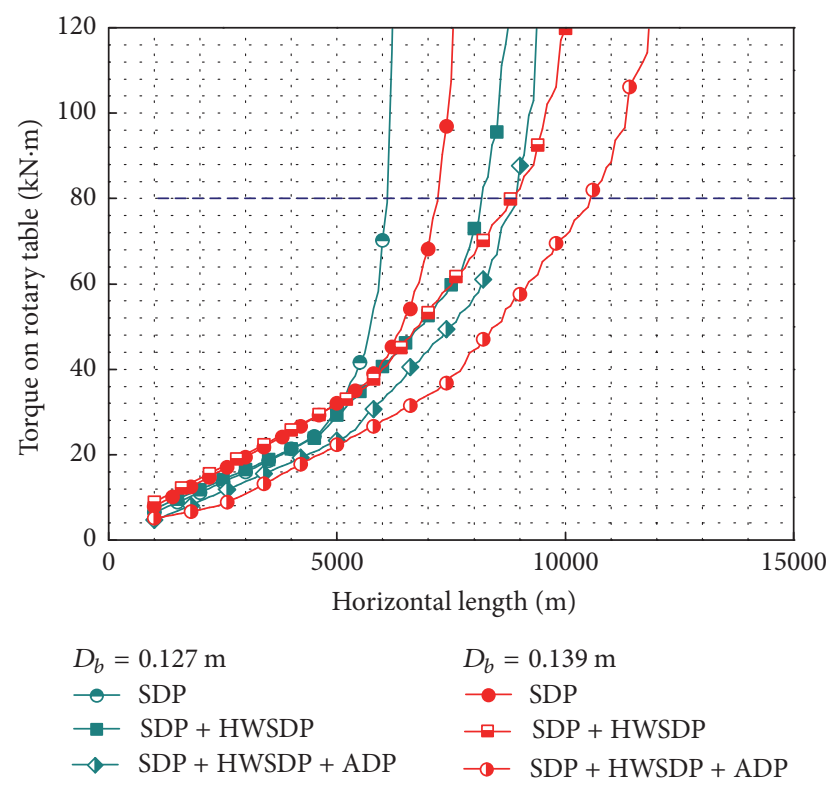

FIgURE 16: Torques on rotary table for different drill string components in rotary drilling mode.

its extending limit, which further increases the contact force between the drill string and wellbore. The increase of contact force further increases the axial friction and torque loss on the drill string. When the axial force on hook is 0 , the torque loss is also very large which usually exceeds the rated torque on the rotary table for a certain drill rig (such as $80 \mathrm{kN} \cdot \mathrm{m}$ in Figure 16). The horizontal extending limits for the $5^{\prime \prime}$ SDP, SDP + HWSDP, and SDP + HWSDP + ADP are, respectively, about $6200 \mathrm{~m}, 8200 \mathrm{~m}$, and $8900 \mathrm{~m}$ and for 5.5" SDP, SDP + HWSDP, and SDP + HWSDP + ADP are, respectively, about $7200 \mathrm{~m}, 8900 \mathrm{~m}$, and $10600 \mathrm{~m}$. The results indicate that the horizontal extending limits can be greatly increased by optimizing drilling mode and drill string components. By adopting rotary drilling mode and using 5.5" SDP + HWSDP + ADP, the horizontal extending limit can break through $10000 \mathrm{~m}$ in this case study.

\section{Discussions on Design Method of Down- Hole Tubular Strings}

The above studies show that extending limits in horizontal drilling are affected by kinds of factors. To improve extending limits, rotary drilling mode, drill rig of high rated torque on rotary table, and high-strength drill string, an appropriate selection of drill string components is indispensable. Among the above factors, high friction force is the primary factor constraining the horizontal wellbore extension and the optimal design of tubular string components is the more effective method to improve extending limits.

Compared with SDP, HWSDP can transfer more weight in the vertical wellbore and inhibit buckling in the horizontal wellbore, but it also leads to more tubular string weight and axial friction force on the nonbuckling section in the horizontal wellbore. Therefore, SDP should be used on the nonbuckling section and HWSDP should be installed on the buckling-prone section. Compared with SDP, ADP can decrease the tubular string weight and axial friction force on the nonbuckling section. However, ADP tends to buckle on the high axial force section, since its critical buckling load is smaller than that of SDP. So, ADP should be installed on the nonbuckling section to reduce the tubular string weight. However, the buckling distribution is unknown before the design of tubular string components and must be calculated with the integral mechanical model. So, one possible way is that the initial drill string components are given, integral mechanical model is called, and then the design model is called. After the drill string components are updated with the design model, the integral mechanical results must be recalculated with the integral mechanical model. Next, the design model is called to obtain new design results of drill string components. The process is repeated several times until the difference of the previous and current design results is small. This method is time-consuming and inefficient, which limits the application of this method. In this paper, the integral mechanical analysis and tubular design are combined together and called only once according to the objective function in horizontal drilling, and the integral mechanical results and design results of drill strings can be obtained simultaneously. Therefore, the new method is rather fast and effective, which can be easily applied to drill design in field operation.

\section{Conclusions}

In this paper, a theoretical model for predicting mechanical extending limits in horizontal drilling is built and the design method of tubular string components for improving extending limits is presented. The main conclusions are summarized as follows:

(1) The horizontal extending limits are underestimated a lot when the effects of friction force on critical helical 
buckling load are neglected. Therefore, the effects of friction force on critical buckling load and load transfer should be both included in the prediction model of extending limits.

(2) The distributions of horizontal extending limits are closely related to the combination of Young's modulus of the tubular string and tubular string weight per unit length. The horizontal extending limits increase faster with the axial force on the starting point of the horizontal wellbore but the final extending limits are smaller for the tubular strings of smaller modulus-weight ratio. Therefore, tubular strings of smaller modulus-weight ratio should be selected for short designed horizontal wellbore and that of larger modulus-weight ratio for long designed horizontal wellbore.

(3) Sliding slack-off is the main limit operation condition and high axial friction factor is the main factor constraining the horizontal extending limits. Rotating drill strings and optimizing the arrangement of multiple kinds of tubular string components in horizontal drilling can greatly increase the horizontal extending limits.

(4) Horizontal extending limits for tubular string components of multiple sizes and types are obviously larger than that of single size and type. The design results indicate that tubular strings of larger diameters and Young's modulus should be installed on the vertical wellbore and the starting section of the horizontal wellbore and tubular strings of smaller diameters and Young's modulus on the end section of the horizontal wellbore.

(5) The optimal design model is called only once to obtain the design results, which greatly increases the design efficiency compared with the traditional design method. The next step is to apply the proposed method to drilling practice.

\section{Appendix}

\section{A. Integral Mechanical Results for Horizontal Wells}

A.1. Pick-Up. The relationship of the axial force and torque on the starting point and the end point of the horizontal section is

$$
\begin{aligned}
F_{\mathrm{hs}} & =F_{\mathrm{he}}-\mu_{1} q L_{h} \\
M_{\text {Ths }} & =M_{\text {The }}+\frac{\mu_{2} D_{b}}{2 \mu_{1}}\left(F_{\mathrm{he}}-F_{\mathrm{hs}}\right),
\end{aligned}
$$

where $L_{h}$ is the length of the horizontal section, $F_{\mathrm{hs}}$ and $M_{\text {Ths }}$ are the axial force and torque on starting point of the horizontal section, and $F_{h e}$ and $M_{T h e}$ are the axial force and torque on end point of the horizontal section.
Assuming that the tubular string touches the upper surface of the wellbore in the build-up section during pickup, the axial force and torque transfer are expressed by

$$
\begin{aligned}
F_{\mathrm{ve}} & =e^{\mu_{1}(\pi / 2)}\left(F_{\mathrm{hs}}-q R \frac{1-\mu_{1}^{2}}{1+\mu_{1}^{2}}\right)+q R \frac{2 \mu_{1}}{1+\mu_{1}^{2}} \\
M_{\mathrm{Tve}} & =M_{\mathrm{Ths}}+\frac{\mu_{2} D_{\mathrm{b}}}{2 \mu_{1}}\left(F_{\mathrm{hs}}-q R-F_{\mathrm{ve}}\right),
\end{aligned}
$$

where $F_{\mathrm{ve}}$ and $M_{\mathrm{Tv}}$ are the axial force and torque on the end point of the vertical section and $R$ is the curvature radius of the build-up wellbore.

For the vertical section, we obtain

$$
\begin{aligned}
F_{\mathrm{vs}} & =F_{\mathrm{ve}}-q L_{v} \\
M_{T \mathrm{vs}} & =M_{T \mathrm{ve}},
\end{aligned}
$$

where $L_{v}$ represents the depth of the kick-off point and $F_{\mathrm{vs}}$ and $M_{T v s}$ are the axial force and torque on top of the vertical wellbore.

On the basis of the above studies, the axial force and torque transfer in the pick-up process can be obtained by combining (A.1) and (A.2) with (A.3).

A.2. Slack-Off. According to (4), the effect of sinusoidal buckling on contact force is rather smaller compared to that of helical buckling. Meanwhile, the sinusoidal buckling stage is very narrow, so the effect of sinusoidal buckling is neglected in the derivation of extending limits. In the following analyses, the sinusoidal buckling is taken as nonbuckling for simplicity. If the tubular string on the end of the horizontal section is in helical buckling state $\left(F_{\text {he }}>F_{h \text { hel }}\right)$, the entire tubular string in horizontal section is in helical buckling mode. Thus, we obtain

$$
\begin{aligned}
\frac{1}{F_{\mathrm{he}}} & =\frac{1}{F_{\mathrm{hs}}}-\frac{\mu_{1} r_{b}}{4 E I} L_{h} \\
M_{\text {Ths }} & =M_{\text {The }}+\frac{\mu_{2} D_{b}}{2 \mu_{1}}\left(F_{\mathrm{hs}}-F_{\mathrm{he}}\right) .
\end{aligned}
$$

If the tubular string on the starting point of the horizontal section is in nonbuckling state $\left(F_{\mathrm{hs}}<F_{h \text { hel }}\right)$, the entire tubular string in horizontal section is in nonbuckling state. Thus, we obtain

$$
\begin{aligned}
F_{\mathrm{hs}} & =F_{\mathrm{he}}+\mu_{1} q L_{h} \\
M_{\text {Ths }} & =M_{\text {The }}+\frac{\mu_{2} D_{b}}{2 \mu_{1}}\left(F_{\mathrm{hs}}-F_{\mathrm{he}}\right) .
\end{aligned}
$$

If the tubular string on the end of the horizontal section is in the nonbuckling state $\left(F_{\text {he }}<F_{h \text { hel }}\right)$ and the tubular string on the starting point of the horizontal section is in helical buckling state $\left(F_{\mathrm{hs}}>F_{\text {hhel }}\right)$, the entire tubular string in horizontal section includes the helical buckling and nonbuckling sections with the critical helical buckling load as the dividing point. Thus, we obtain

$$
\begin{aligned}
\frac{1}{F_{\text {he }}} & =\frac{1}{F_{h \text { hel }}}-\frac{\mu_{1} r_{b}}{4 E I}\left(L_{h}-\frac{F_{\text {hel }}-F_{\text {hhel }}}{\mu_{1} q}\right) \\
M_{\text {Ths }} & =M_{\text {The }}+\frac{\mu_{2} D_{b}}{2 \mu_{1}}\left(F_{\text {hs }}-F_{\text {he }}\right),
\end{aligned}
$$


where $F_{h \text { hel }}$ is the critical helical buckling load in the horizontal section and is calculated by (Chen et al. [20])

$$
F_{h \text { hel }}=\lambda_{f} \cdot 2 \sqrt{2} \sqrt{\frac{E I q}{r_{b}}},
$$

in which $\lambda_{f}$ is the amendment factor due the friction force and is calculated by (Gao and Huang [21])

$$
\lambda_{f}=1+\frac{30+7 \pi^{2}}{30 \pi} \mu_{1}
$$

Note that $\lambda_{f}$ is equal to 1 for the zero friction factor case.
Assuming that the tubular string touches the bottom surface of the wellbore in the build-up section during slackoff, the axial force and torque transfer are expressed by

$$
\begin{aligned}
F_{\mathrm{ve}} & =e^{\mu_{1}(\pi / 2)}\left(F_{\mathrm{hs}}-q R \frac{1-\mu_{1}^{2}}{1+\mu_{1}^{2}}\right)+q R \frac{2 \mu_{1}}{1+\mu_{1}^{2}} \\
M_{T \mathrm{ve}} & =M_{T \mathrm{hs}}-\frac{\mu_{2} D_{b}}{2 \mu_{1}}\left(F_{\mathrm{hs}}-q R-F_{\mathrm{ve}}\right) .
\end{aligned}
$$

For the tubular string in the vertical section, the axial force and torque transfer are expressed by

$$
\begin{aligned}
F_{\mathrm{vs}} & = \begin{cases}F_{\mathrm{ve}}-q L_{v} & F_{\mathrm{ve}} \leq F_{v \text { hel }} \\
F_{v \max }\left[a \tanh \left(\frac{F_{\mathrm{ve}}}{F_{v \max }}\right)-a \tanh \left(\frac{F_{v \text { hel }}}{F_{v \max }}\right)\right]-q L_{v}+F_{v \text { hel }} & F_{\mathrm{ve}}>F_{v \text { hel }}\end{cases} \\
M_{T \mathrm{vs}} & = \begin{cases}M_{T \mathrm{ve}} & F_{\mathrm{ve}} \leq F_{v \text { hel }} \\
M_{T \mathrm{ve}}+\frac{\mu_{2} D_{b}}{2 \mu_{1}}\left(F_{\mathrm{vs}}+q L_{v}-F_{\mathrm{ve}}\right) & F_{\mathrm{ve}}>F_{v \text { hel }},\end{cases}
\end{aligned}
$$

where $F_{\text {vhel }}$ is the critical helical buckling load in vertical wellbore and is calculated by (Wu, [22])

$$
F_{\text {vhel }}=\lambda_{f} \cdot 5.55 \sqrt[3]{E I q^{2}}
$$

The term $F_{v \max }$ is the maximum axial force in the vertical wellbore and is calculated by

$$
F_{v \max }=2 \sqrt{\frac{E I q}{\mu_{1} r_{b}}} .
$$

On the basis of the above studies, the axial force and torque transfer in the slack-off process can be obtained by combining (A.4)-(A.6) and (A.9) with (A.10).

\section{B. Mechanical Extending Limits for Horizontal Wells}

B.1. Pick-Up. The entire horizontal well can be divided into vertical-build and horizontal sections by the starting point of the horizontal section. The axial force transfer is calculated by

$$
\begin{aligned}
& F_{\mathrm{ve}}=F_{\mathrm{hs}}+\Delta F_{b} \\
& F_{\mathrm{vs}}=F_{\mathrm{hs}}+\Delta F_{b}+\Delta F_{v},
\end{aligned}
$$

where $\Delta F_{b}$ and $\Delta F_{v}$ are the axial force losses in the vertical and build-up wellbores and calculated by (A.2) and (A.3).

According to the constraint conditions of the rated pickup force of the drill rig and tubular yield strength at the top and bottom ends of the vertical section, the minimum axial force at the starting point of the horizontal section is calculated by

$$
F_{\mathrm{hs}}{ }^{l}=F_{\mathrm{hs}}{ }^{l}\left(M_{\mathrm{Ths}}\right)=\max \left(-\left[\sigma_{m}\right]_{\mathrm{ve}} \cdot A_{s}-\Delta F_{b}, \max \left(-\left[\sigma_{m}\right]_{\mathrm{vs}} \cdot A_{s},-T_{\mathrm{rig}}{ }^{u}\right)-\Delta F_{b}-\Delta F_{v}\right),
$$

where $A_{s}$ is the area of the cross section of the tubular string and $\left[\sigma_{m}\right]_{\mathrm{vs}}$ and $\left[\sigma_{m}\right]_{\mathrm{ve}}$ are the allowable axial stresses at the starting and end points of the vertical section and are calculated by

$$
\begin{aligned}
& {\left[\sigma_{m}\right]_{\mathrm{ve}}=\sqrt{[\sigma]^{2}-3\left[\frac{16 M_{T \mathrm{vs}} D_{b}}{\pi\left(D_{b}^{4}-D_{b i}{ }^{4}\right)}\right]^{2}}} \\
& {\left[\sigma_{m}\right]_{\mathrm{ve}}=\sqrt{[\sigma]^{2}-3\left[\frac{16 M_{T \mathrm{ve}} D_{b}}{\pi\left(D_{b}^{4}-D_{b i}{ }^{4}\right)}\right]^{2}}-\frac{E \kappa_{b} D_{b}}{2} .}
\end{aligned}
$$

Then, the extending limit of the horizontal section during pick-up is calculated by (A.1); namely,

$$
L_{h}=\frac{F_{\mathrm{he}}-F_{\mathrm{hs}}{ }^{l}}{q \cdot \mu_{1}} .
$$

For the sliding pick-up process, the effect of torque is neglected in the above derivation. For the rotary pick-up process, the effect of torque cannot be neglected in (B.3). Similar to (B.1), we obtain 


$$
\begin{aligned}
& M_{T \mathrm{ve}}=M_{T \mathrm{hs}}+\Delta M_{T b} \\
& M_{T \mathrm{vs}}=M_{T \mathrm{hs}}+\Delta M_{T b}+\Delta M_{T v},
\end{aligned}
$$

where $\Delta M_{T v}$ and $\Delta M_{T b}$ are the torque losses in the vertical and build-up sections.
According to the constraint conditions of the rated torque of the drill rig and tubular yield strength, the maximum torque at the starting point of the horizontal section is calculated by

$$
M_{T h s}{ }^{u}=M_{T h s}{ }^{u}\left(F_{\mathrm{hs}}\right)=\min \left(\frac{2 I_{\rho}}{D_{b}}\left[\tau_{c}\right]_{\mathrm{hs}}, \frac{2 I_{\rho}}{D_{b}}\left[\tau_{c}\right]_{\mathrm{ve}}-\Delta M_{T b}, \min \left(\frac{2 I_{\rho}}{D_{b}}\left[\tau_{c}\right]_{\mathrm{vs}}, T_{\mathrm{rig}}{ }^{u}\right)-\Delta M_{T b}-\Delta M_{T v}\right),
$$

where the allowable shear stresses at the starting point of the horizontal section, the end point of the vertical section, and the starting point of the vertical section are, respectively, calculated by

$$
\begin{aligned}
& {\left[\tau_{c}\right]_{\mathrm{hs}}=\frac{1}{\sqrt{3}} \sqrt{[\sigma]^{2}-\left(\frac{\left|F_{\mathrm{hs}}\right|}{A_{s}}+E \kappa_{b} \frac{D_{b}}{2}\right)^{2}}} \\
& {\left[\tau_{c}\right]_{\mathrm{ve}}=\frac{1}{\sqrt{3}} \sqrt{[\sigma]^{2}-\left(\frac{\left|F_{\mathrm{ve}}\right|}{A_{s}}+E \kappa_{b} \frac{D_{b}}{2}\right)^{2}}} \\
& {\left[\tau_{c}\right]_{\mathrm{vs}}=\frac{1}{\sqrt{3}} \sqrt{[\sigma]^{2}-\left(\frac{\left|F_{\mathrm{vs}}\right|}{A_{s}}\right)^{2}} .}
\end{aligned}
$$

Then, the extending limit of the horizontal section during pick-up is calculated by (A.1); namely,

$$
L_{h}=\frac{M_{T h s}^{u}-M_{T h e}}{\mu_{2} D_{b} q / 2} \text {. }
$$

B.2. Slack-Off. Similar to the analysis for pick-up operation, the minimum axial force and torque at the starting point of the horizontal section during slack-off can be obtained by considering the constraint conditions in the vertical-build section and are calculated by (B.2) and (B.6).

When the axial force on the top of the vertical section reaches the minimum slack-off force of the drill rig, the down-hole tubular string reaches its extending limit. Then, the expression $-F_{\mathrm{hs}}=T_{\mathrm{rig}}{ }^{l}$ is satisfied and the maximum axial force on the starting point of the horizontal section is calculated by

$$
F_{\mathrm{hs}}^{u}=-T_{\text {rig }}^{u}-\Delta F_{b}-\Delta F_{v} \text {. }
$$

For tubular strings under slack-off process in horizontal wells, it is the maximum axial force $F_{\mathrm{hs}}{ }^{u}$ rather than the minimum axial force $F_{\mathrm{hs}}{ }^{l}$ which limits the horizontal wellbore extension. This is to say, the minimum axial force $F_{\mathrm{hs}}{ }^{l}$ and maximum torque $M_{T h s}{ }^{u}$ loss are the available constraint factors in horizontal drilling. Further introducing the axial

force transfer in the horizontal section, the extending limit of the horizontal section is calculated by

$$
\begin{aligned}
& L_{h} \\
& = \begin{cases}\frac{F_{\mathrm{hs}}{ }^{u}-F_{\mathrm{he}}}{\mu_{1} q} & F_{\text {hhel }} \geq F_{\mathrm{hs}}{ }^{u}>F_{\mathrm{he}} \\
\frac{4 E I}{\mu_{1} r_{b}}\left(\frac{1}{F_{h \mathrm{hel}}}-\frac{1}{F_{\mathrm{hs}}{ }^{u}}\right)+\frac{F_{h \mathrm{hel}}-F_{\mathrm{he}}}{\mu_{1} q} & F_{\mathrm{hs}}{ }^{u}>F_{h \text { hel }}>F_{\mathrm{he}} \\
\frac{4 E I}{\mu_{1} r_{b}}\left(\frac{1}{F_{\mathrm{he}}}-\frac{1}{F_{\mathrm{hs}}{ }^{u}}\right) & F_{\mathrm{hs}}{ }^{u}>F_{\mathrm{he}} \geq F_{\text {hhel }} \\
0 & \text { others. }\end{cases}
\end{aligned}
$$

Note that the extending limit in the slack-off operation due to the maximum torque is identical with (B.8).

\section{Nomenclature}

ADP:

CDP:

HWSDP:

SDP:

$A_{s}$ :

$D_{w}, D_{b}$, and $D_{c}$ :

$D_{c 1}, D_{c 2}$ :

$d_{\text {tub }}$ :

$E I:$

$F$ :

$F_{\mathrm{vs}}, F_{\mathrm{ve}}$ :

$F_{\text {hs }}, F_{\text {he }}$ :

$F_{\mathrm{hs}}{ }^{l}$ :
Aluminum drill string

Composite drill string

Heavy weight steel drill string

Steel drill string

Area of tubular string cross section, $\mathrm{m}^{2}$

: Diameters of wellbore, tubular string

body, and connector, $\mathrm{m}$

The critical vertical depth within which the tubular string in vertical wellbore is in the nonbuckling state in the slack-off mode, $\mathrm{m}$; the critical vertical depth exceeding which helical buckling occurs on the horizontal section, $\mathrm{m}$

Relevant parameters of a specified tubular string

Bending stiffness of the tubular string, $\mathrm{N} \cdot \mathrm{m}^{2}$

Axial force on the tubular string, N Axial forces at the top and bottom points of the vertical wellbore, $\mathrm{N}$ Axial forces at the starting and end points of the horizontal wellbore, $\mathrm{N}$ The minimum axial force on the starting point of the horizontal section under which the tubular strings in the vertical-build wellbore are not yielded, and the axial tensile force on ground is not larger than the rated axial force on hook in the pick-up operation, $\mathrm{N}$ 


\begin{tabular}{|c|c|c|c|}
\hline \multirow[t]{4}{*}{$F_{\mathrm{hs}}{ }^{u}:$} & $\begin{array}{l}\text { The maximum axial force on } \\
\text { the starting point of the }\end{array}$ & $M_{\text {Tths }}^{l}:$ & $\begin{array}{l}\text { Threshold value of torque for } \\
\text { rock breaking, } \mathrm{N} \cdot \mathrm{m}\end{array}$ \\
\hline & $\begin{array}{l}\text { horizontal section under } \\
\text { which the axial tensile force }\end{array}$ & $M_{\text {Trig }}:$ & $\begin{array}{l}\text { Rated torque of the drill rig, } \\
\mathrm{N} \cdot \mathrm{m}\end{array}$ \\
\hline & $\begin{array}{l}\text { on ground is not smaller than } \\
\text { the minimum axial force on }\end{array}$ & $\Delta M_{T v}, \Delta M_{T b}$ & $\begin{array}{l}\text { Torque losses in the vertical } \\
\text { and build-up wellbores, N·m }\end{array}$ \\
\hline & $\begin{array}{l}\text { hook in the slack-off } \\
\text { operation, } \mathrm{N}\end{array}$ & $m_{\text {max,lat }}, m_{\text {max,inter }}, m_{\text {max,intra }}:$ & $\begin{array}{l}\text { Dimensionless maximum } \\
\text { bending moments under }\end{array}$ \\
\hline$F_{\text {hs_hel }}$ : & $\begin{array}{l}\text { Axial force at the starting } \\
\text { point of the horizontal } \\
\text { wellbore when helical } \\
\text { buckling just occurs, } \mathrm{N}\end{array}$ & $n_{t}:$ & $\begin{array}{l}\text { nonbuckling/lateral buckling, } \\
\text { interhelical buckling, and } \\
\text { intrahelical buckling modes } \\
\text { Contact force on a local }\end{array}$ \\
\hline$F_{\mathrm{ths}}^{l}:$ & $\begin{array}{l}\text { Threshold value of axial force } \\
\text { for rock breaking, } \mathrm{N}\end{array}$ & & $\begin{array}{l}\text { tubular string with } \\
\text { connectors per unit length, } \\
\mathrm{N} / \mathrm{m}\end{array}$ \\
\hline$F_{\text {sin }}, F_{\text {hel }}:$ & Critical buckling loads for & $n_{4}:$ & $\begin{array}{l}\text { Safety factor of the tubular } \\
\text { string failure }\end{array}$ \\
\hline \multirow[t]{3}{*}{$F_{h \sin }, F_{\text {hhel }}:$} & $\begin{array}{l}\text { helical buckling modes, } \mathrm{N} \\
\text { Critical buckling loads for }\end{array}$ & $q:$ & $\begin{array}{l}\text { Tubular string weight per unit } \\
\text { length, N/m }\end{array}$ \\
\hline & $\begin{array}{l}\text { sinusoidal buckling and } \\
\text { helical buckling modes in }\end{array}$ & $r_{b}:$ & $\begin{array}{l}\text { Radial clearance between the } \\
\text { tubular string and wellbore, } m\end{array}$ \\
\hline & vertical wellbores, $\mathrm{N}$ & $R:$ & Curvature radius of the \\
\hline \multirow[t]{2}{*}{$F_{v \text { hel }}:$} & Critical helical buckling load & & build-up wellbore, m \\
\hline & for vertical wellbore, $\mathrm{N}$ & $s:$ & Axial distance along the \\
\hline \multirow[t]{2}{*}{$F_{v \max }:$} & Limit value of axial force on & & wellbore axis, $\mathrm{m}$ \\
\hline & $\begin{array}{l}\text { the helical buckling section in } \\
\text { the vertical wellbore, } \mathrm{N}\end{array}$ & $T_{\text {rig }}^{u}, T_{\text {rig }}^{l}:$ & $\begin{array}{l}\text { Maximum and minimum } \\
\text { pick-up forces of the drill rig, }\end{array}$ \\
\hline \multirow{2}{*}{$\Delta F_{v}, \Delta F_{b}$} & Axial force losses in the & & $\mathrm{N} \cdot \mathrm{m}$ \\
\hline & $\begin{array}{l}\text { vertical and build-up } \\
\text { wellbores, } \mathrm{N}\end{array}$ & $\alpha:$ & $\begin{array}{l}\text { Inclination angle of the } \\
\text { wellbore, rad }\end{array}$ \\
\hline$I_{\rho}:$ & $\begin{array}{l}\text { Polar inertia moment of } \\
\text { tubular string, } \mathrm{m}^{4}\end{array}$ & $\lambda_{f}:$ & $\begin{array}{l}\text { The amendment factor of } \\
\text { critical helical buckling load }\end{array}$ \\
\hline$K_{\alpha}:$ & $\begin{array}{l}\text { Bending curvature of the } \\
\text { build-up wellbores, } \mathrm{m}^{-1}\end{array}$ & & $\begin{array}{l}\text { due to the existence of } \\
\text { friction factor }\end{array}$ \\
\hline$L_{h}:$ & $\begin{array}{l}\text { Length of the horizontal } \\
\text { section, } \mathrm{m}\end{array}$ & $\kappa_{b}:$ & $\begin{array}{l}\text { Bending curvature of the } \\
\text { tubular string, } \mathrm{m}^{-1}\end{array}$ \\
\hline$L_{h \_ \text {hel }}:$ & $\begin{array}{l}\text { Length of the horizontal } \\
\text { section when helical buckling } \\
\text { just occurs, m }\end{array}$ & $\mu_{1}, \mu_{2}:$ & $\begin{array}{l}\text { The axial and circumferential } \\
\text { components of the friction } \\
\text { factor }\end{array}$ \\
\hline$L_{v}:$ & $\begin{array}{l}\text { Length of the vertical section, } \\
\mathrm{m}\end{array}$ & $\sigma:$ & $\begin{array}{l}\text { Maximum equivalent stress } \\
\text { on the tubular string, } \mathrm{N} / \mathrm{m}\end{array}$ \\
\hline$M_{b}:$ & $\begin{array}{l}\text { Bending moment on the } \\
\text { tubular string, } \mathrm{N} \cdot \mathrm{m}\end{array}$ & $\sigma_{b}:$ & $\begin{array}{l}\text { Maximum bending stress on } \\
\text { the tubular string, } \mathrm{N} / \mathrm{m}^{2}\end{array}$ \\
\hline$M_{T}:$ & $\begin{array}{l}\text { Torque on the tubular string, } \\
\mathrm{N} \cdot \mathrm{m}\end{array}$ & {$[\sigma]:$} & $\begin{array}{l}\text { Allowable stress of tubular } \\
\text { string failure, } \mathrm{N} / \mathrm{m}^{2}\end{array}$ \\
\hline$M_{T \mathrm{vs}}, M_{T \mathrm{ve}}:$ & $\begin{array}{l}\text { Torques at the top and } \\
\text { bottom points of the vertical } \\
\text { wellbore, } N \cdot \mathrm{m}\end{array}$ & $\sigma_{m}:$ & $\begin{array}{l}\text { Average axial stress on the } \\
\text { cross section of the tubular } \\
\text { string due to axial force, } \mathrm{N} / \mathrm{m}^{2}\end{array}$ \\
\hline$M_{\text {Ths }}, M_{\text {The }}:$ & $\begin{array}{l}\text { Torques at the starting and } \\
\text { end points of the horizontal } \\
\text { wellbore, } \mathrm{N} \cdot \mathrm{m}\end{array}$ & {$\left[\sigma_{m}\right]_{\mathrm{vs}},\left[\sigma_{m}\right]_{\mathrm{ve}}:$} & $\begin{array}{l}\text { Allowable axial stresses at the } \\
\text { starting and end points of the } \\
\text { vertical section, } \mathrm{N} / \mathrm{m}^{2}\end{array}$ \\
\hline \multirow[t]{3}{*}{$M_{T h s}{ }^{u}:$} & $\begin{array}{l}\text { The maximum torque on the } \\
\text { starting point of the }\end{array}$ & $\sigma_{s}:$ & $\begin{array}{l}\text { Yield strength of the tubular } \\
\text { string, N/m }\end{array}$ \\
\hline & $\begin{array}{l}\text { horizontal section under } \\
\text { which the tubular strings in }\end{array}$ & $\tau_{c}:$ & $\begin{array}{l}\text { Maximum shear stress on the } \\
\text { tubular string, } N / \mathrm{m}^{2}\end{array}$ \\
\hline & $\begin{array}{l}\text { the vertical-build wellbore are } \\
\text { not yielded, and torque on } \\
\text { ground is not larger than the } \\
\text { rated torque of the drill rig, } \\
\mathrm{N} \cdot \mathrm{m}\end{array}$ & {$\left[\tau_{c}\right]_{\mathrm{vs}},\left[\tau_{c}\right]_{\mathrm{ve}},\left[\tau_{c}\right]_{\mathrm{hs}}:$} & $\begin{array}{l}\text { Allowable shear stresses at the } \\
\text { starting and end points of the } \\
\text { vertical section and starting } \\
\text { point of the horizontal } \\
\text { section, } \mathrm{N} / \mathrm{m}^{2} \text {. }\end{array}$ \\
\hline
\end{tabular}




\section{Conflicts of Interest}

The authors declare that they have no conflicts of interest.

\section{Acknowledgments}

The authors gratefully acknowledge the financial support from the Natural Science Foundation of China (Grant no. 51521063), National Science Foundation for Distinguished Young Scholars of China (Grant no. 11325211), and China Postdoctoral Science Foundation (Grant no. 2016M601044). This research is also supported by National Key R\&D Projects (Grant no. 2016YFC0303303) and the National Science and Technology Major Project (2017ZX05009-003).

\section{References}

[1] J. Wu and H. C. Juvkam-Wold, "Coiled tubing buckling implication in drilling and completing horizontal wells," SPE Drilling \& Completion, vol. 10, SPE-26336, no. 1, pp. 16-21, 1995.

[2] C. J. Mason and A. Judzis, "Extended-reach drilling-what is the limit?" in Proceedings of the SPE Annual Technical Conference and Exhibition, SPE-48943, pp. 87-98, New Orleans, LA, USA, September 1998.

[3] Wang Z. and X. Guo, "Hydraulic extended limitation of extended-reach well," Drilling \& Production Technology, vol. 1, no. 4, pp. 1-3, 2008.

[4] D. Gao, C. Tan, and H. Tang, "Limit analysis of extended reach drilling in South China Sea," Petroleum Science, vol. 6, no. 2, pp. 166-171, 2009.

[5] T. Yan, F. Zhang, W. Liu et al., "Mechanical analysis of the limit extended capacity for an extended reach well," Drilling \& Production Technology, vol. 33, no. 1, pp. 4-7, 2010.

[6] X. Li, D. Gao, Y. Zhou et al., "A model for extended-reach limit analysis in offshore horizontal drilling based on formation fracture pressure," Journal of Petroleum Science \& Engineering, vol. 146, pp. 400-408, 2016.

[7] X. Li, D. Gao, Y. Zhou et al., "Study on open-hole extendedreach limit model analysis for horizontal drilling in shales," Journal of Natural Gas Science \& Engineering, vol. 34, pp. 520533, 2016.

[8] G. Peng and H. Zhao, "Drillstem design for horizontal holes," China Petroleum Machinery, vol. 19, no. 12, pp. 1-6, 1991.

[9] Z. Han, "Optimum design of drillstring in horizontal drilling," Journal of the University of Petroleum, vol. 21, no. 5, pp. 23-26, 1997.

[10] F. Allen, P. Tooms, G. Conran et al., "Extended-reach drilling: breaking the 10-km barrier," Oilfield Review, vol. 9, pp. 32-47, 1997.

[11] Y. Xia, J. Chen, R. Xu et al., "Optimization design methods of drilling strings in extended reach wells," Oil Drilling \& Production Technology, vol. 30, no. 6, pp. 37-41, 2008.

[12] C. A. Johancsik, D. B. Friesen, and R. Dawson, "Torque and drag in directional wells-prediction and measurement," Journal of Petroleum Technology, vol. 36, SPE-11380, no. 6, pp. 987-992, 1984.

[13] H. S. Ho, "An improved modeling program for computing the torque and drag in directional and deep wells," in Proceedings of the SPE Annual Technical Conference and Exhibition, SPE-18047, pp. 407-418, Houston, TX, USA, October 1988.
[14] D. Gao, X. Liu, and B. Xu, Prediction and Control of Wellbore Trajectory, China University of Petroleum Press, Dongying, China, 1994.

[15] R. F. Mitchell, A. Bjorset, and G. Grindhaug, "Drillstring analysis with a discrete torque/drag model," SPE Drilling \& Completion, vol. 30, SPE-163477, no. 1, 2013.

[16] W. Huang and W. Gao, "A local mechanical model of downhole tubular strings and its amendment on the integral model," in Proceedings of the IADC/SPE Asia Pacific Drilling Technology Conference, SPE-180613, Singapore, August 2016.

[17] Z. Han, "Study on axial force calculating and strength testing for drillstring in curved hole," Petroleum Drilling Techniques, no. 1, pp. 7-12, 1996.

[18] M. Mehrabi and S. Miska, "How far can we push the boundary of horizontal drilling? a rivalry between wellbore friction and drillpipe buoyant weight and stiffness," in Proceedings of the SPE Annual Technical Conference and Exhibition, Houston, TX, USA, September 2015.

[19] M. Y. Gelfgat, V. S. Basovich, A. Adelman et al., "Aluminium alloy tubulars-assessment for ultralong well construction," in Proceedings of the SSPE Annual Technical Conference and Exhibition, November 2007.

[20] Y. Chen, Y. Lin, and J. B. Cheatham, "Tubing and casing buckling in horizontal wells (includes associated papers 21257 and 21308)," SPE Journal of Petroleum Technology, vol. 42, no. 2, article 191, pp. 140-141, 1990.

[21] D.-L. Gao and W.-J. Huang, "A review of down-hole tubular string buckling in well engineering," Petroleum Science, vol. 12, no. 3, pp. 443-457, 2015.

[22] J. Wu, Buckling behavior of pipes in directional and horizontal wells [PhD dissertation], Texas A \& M University, 1992. 


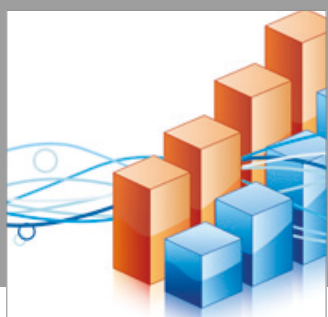

Advances in

Operations Research

vatersals

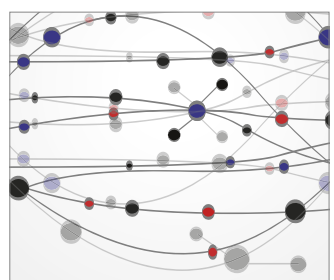

\section{The Scientific} World Journal
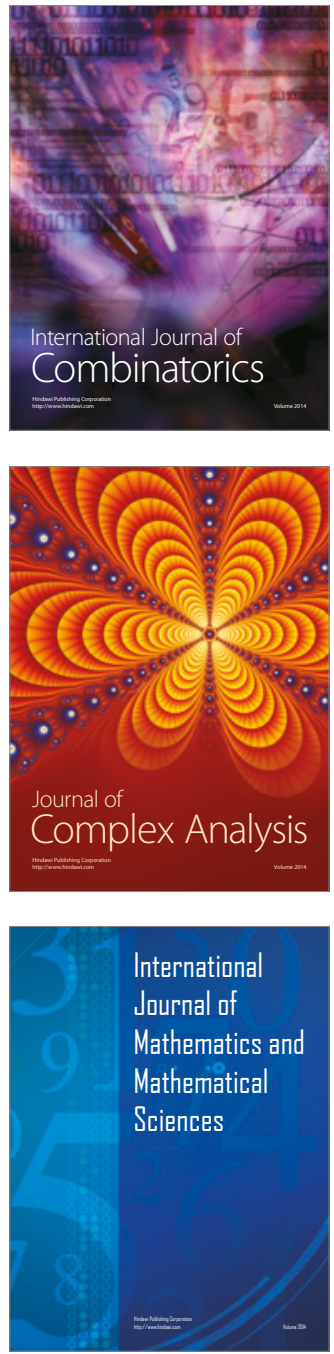
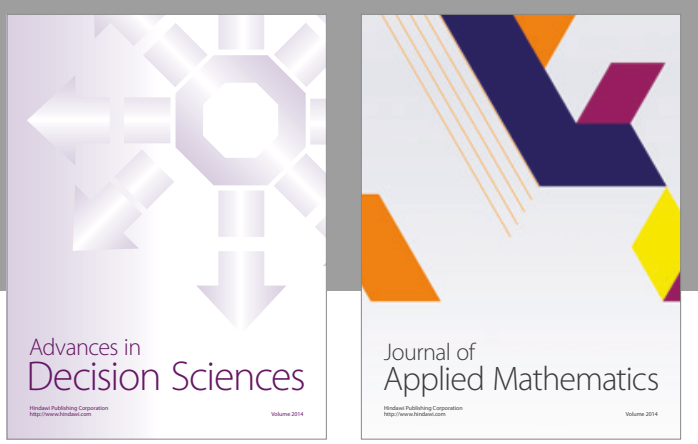

Algebra

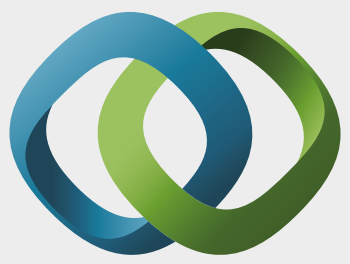

\section{Hindawi}

Submit your manuscripts at

https://www.hindawi.com
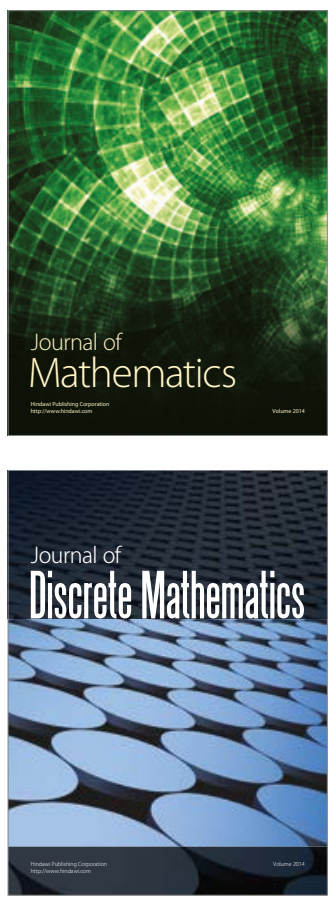

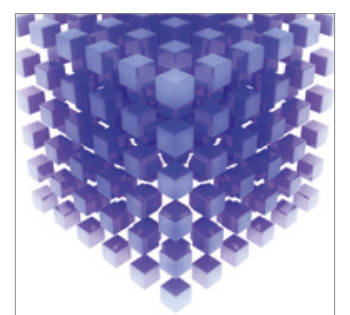

Mathematical Problems in Engineering
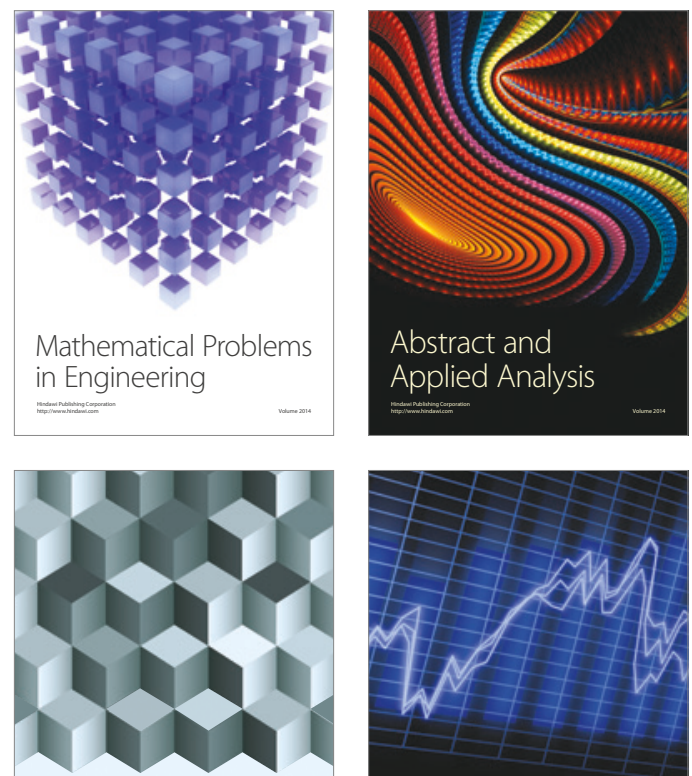

Journal of

Function Spaces

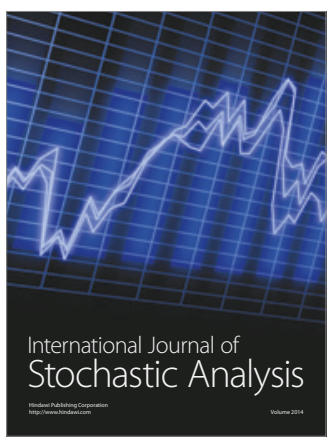

Probability and Statistics
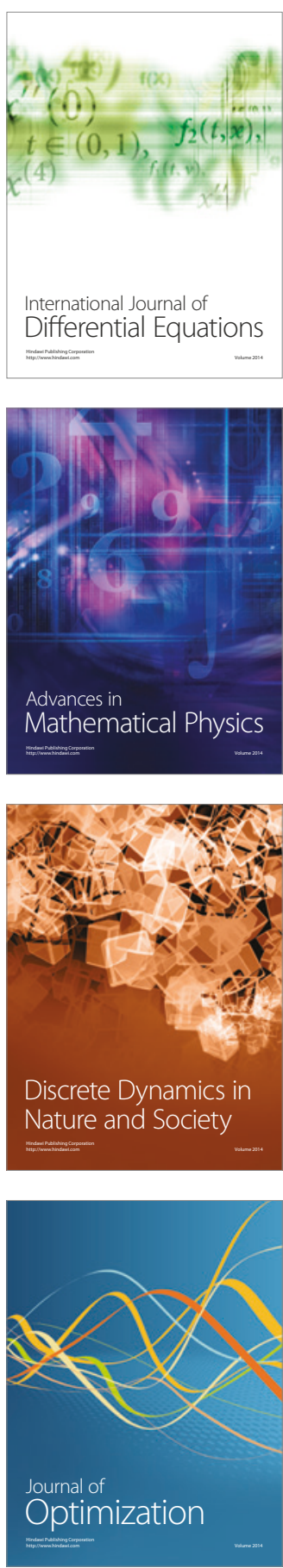